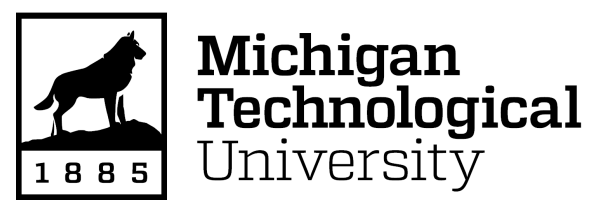

Michigan Technological University Digital Commons @ Michigan Tech

Dissertations, Master's Theses and Master's Reports

2020

\title{
The impacts of accessibility on vulnerability of place in Comfort Castle, Jamaica
}

Heather Thole

Michigan Technological University, hthole@mtu.edu

Copyright 2020 Heather Thole

\section{Recommended Citation}

Thole, Heather, "The impacts of accessibility on vulnerability of place in Comfort Castle, Jamaica", Open Access Master's Thesis, Michigan Technological University, 2020.

https://doi.org/10.37099/mtu.dc.etdr/1073

Follow this and additional works at: https://digitalcommons.mtu.edu/etdr

Part of the Geology Commons, Human Geography Commons, and the Nature and Society Relations Commons 


\title{
THE IMPACTS OF ACCESSIBILITY ON VULNERABILITY OF PLACE IN COMFORT CASTLE, JAMAICA
}

\author{
By \\ Heather R. Thole \\ A THESIS \\ Submitted in partial fulfillment of the requirements for the degree of \\ MASTER OF SCIENCE \\ In Geology \\ MICHIGAN TECHNOLOGICAL UNIVERSITY \\ 2020 \\ (C) 2020 Heather R. Thole
}


This thesis has been approved in partial fulfillment of the requirements for the Degree of MASTER OF SCIENCE in Geology.

Department of Geological and Mining Engineering Sciences

\author{
Thesis Co-Advisor: $\quad$ Greg Waite \\ Thesis Co-Advisor: $\quad$ Kari Henquinet \\ Committee Member: $\quad$ Rudiger Escobar Wolf \\ Department Chair: John Gierke
}




\section{Table of Contents}

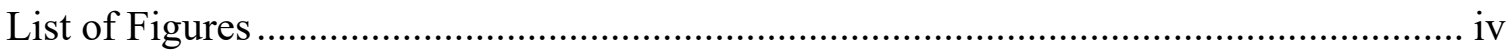

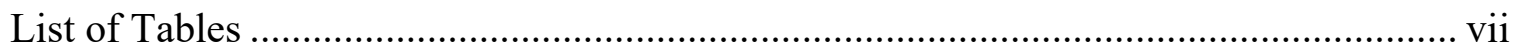

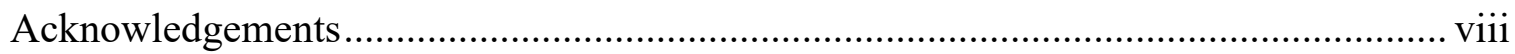

List of Abbreviations …………………………………....................................... ix

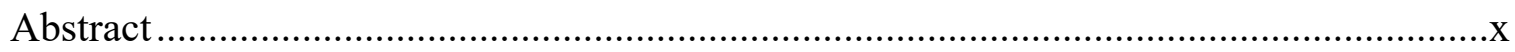

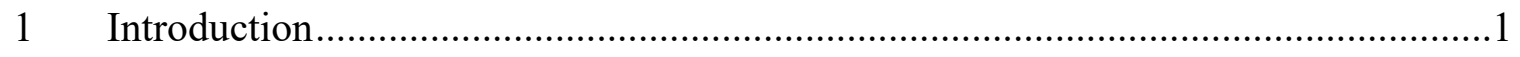

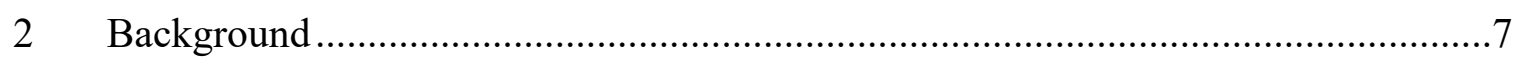

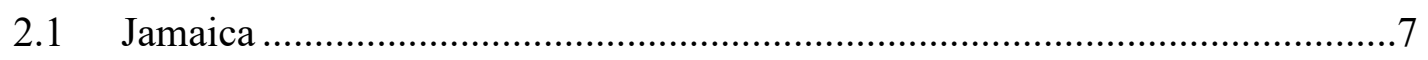

2.2 Study Location: Comfort Castle, Jamaica ……………................................10

2.2.1 Landslide Hazards.......................................................................15

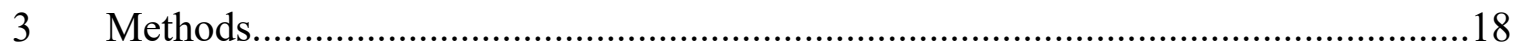

$3.1 \quad$ Ethnographic Analysis ........................................................................18

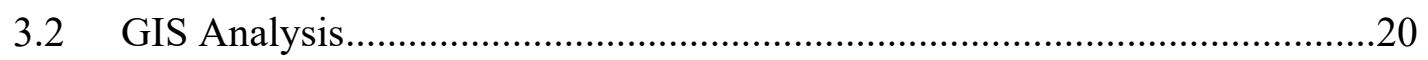

3.2.1 Road Susceptibility to Landslide Hazards Analysis .........................20

3.2.2 Population Impact Analysis ............................................................22

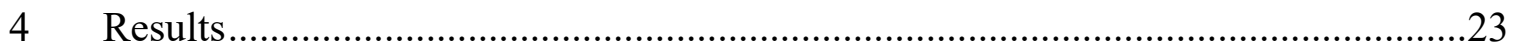

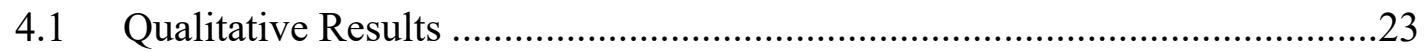

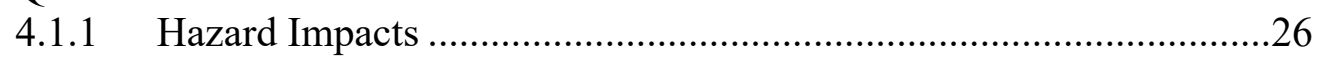

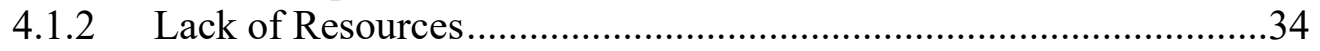

4.1.3 Finacial Limitations …………………………...............................35

4.1.4 Personal Experience, Education, and Preparedness............................36

4.1.5 Lack of Political Power and Represenation and Government

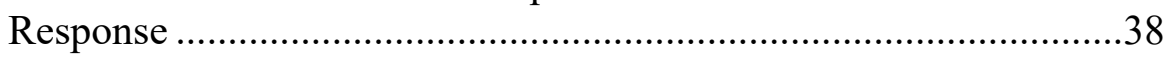

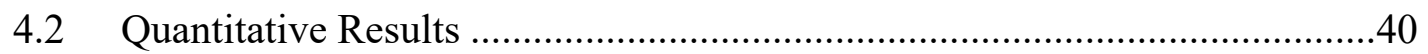

4.2.1 Road Susceptibility to Landslide Hazards ........................................40

4.2.2 Population Impact ..........................................................................42 


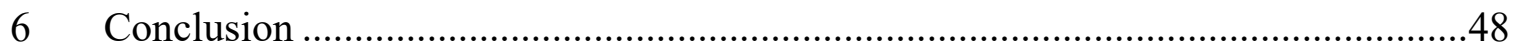

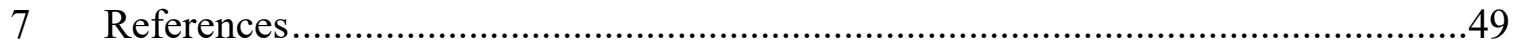

Appendix A: Semi-formal Interview Questions …………….......................................52

Appendix B: Rio Grande Valley Raod Interview Questions .............................................54

Appendix C: Publisher Permission to Reproduce PAR Model ..........................................55 


\section{List of Figures}

Figure 2.1.1: Map of the 14 parishes in Jamaica ............................................................

Figure 2.2.1: Map of study location.......................................................................11

Figure 2.2.2: The Comfort Castle Enumeration Distrcit Consists of Ginger House, Comfort Castle, and Mill Bank

Figure 2.2.1.1: Landslide susceptibility and zonation in Portland produced using GIS data from the Jamaica Mines and Geology Division from Suresh Bhala's reserach .....16

Figure 3.2.1: Intersection geoprocessing tool result. Input shows the two feature classes (one yellow and one blue). Output show the overlap of those two feature classes. https://pro.arcgis.com/en/pro-app/tool-reference/analysis/intersect.htm

Figure 4.1.1: Pressure and Release (PAR) Model showing the progression of vulnerability and interaction between hazards and vulnerability that produce disasters (Wisner et al., 2004)

Figure 4.1.1.1: Percentage of responses for the most damaging natural hazard in Comfort Castle gathered from semi-formal interviews with residents .27

Figure 4.1.1.2: Percentage of the most frequent natural hazards that affects Comfort Castle gathered from semi-formal interviews with residents

Figure 4.1.1.3: Ginger House participatory map drawn during a focus group session.......31

Figure 4.1.1.4: Comfort Castle participatory map drawn during a focus group session... 32

Figure 4.1.1.5: Mill Bank participatory map drawn during a focus group session.............33

Figure 4.2.1.1: Results from using the Intersection geoprocessing tool to determine landslide hazard susceptibility of the Rio Grande Valley Road. The Intersection map is the product of overlapping features from the landslide susceptibility and Rio Grande Valley Road feature classes.

Figure 4.2.1.2: A majority of the Rio Grande Valley Road at risk to landslide hazards. $71.4 \%$ of the road segments intersect with moderate, moderately high, high, and very high landslide susceptibility zones

Figure 4.2.2.1: The potential number of people impacted if a landslide blocked the Rio Grande Valley Road near the communities of Windsor or Friday. At both locations the road intersects with high landslide susceptibility. 
Figure 5.1: Three locations where areas of higher susceptibility could impact lower susceptibility areas that intersect the Rio Grande Valley Road, creating a higher level of susceptibility for that road segment 


\section{List of Tables}

Figure 3.2.1: Parameters used to transform layers between WGS84 and JAD69

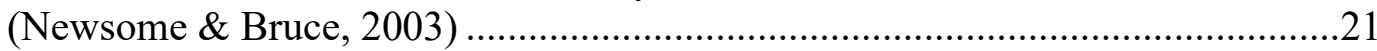

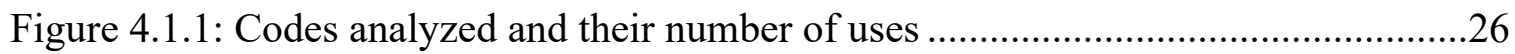

Figure 4.2.1.1: Rio Grande Valley road segment detail for the five levels of landsldie

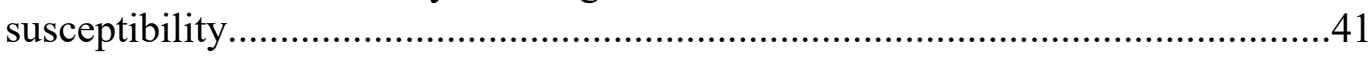




\section{Acknowledgements}

Comfort Caste residents, thank you for sharing your insight, knowledge, and personal experience about local culture, everyday life, and experience with natural disasters. The richness and quality of data used to drive this thesis are due to your willingness and desire to contribute. A thank you is not enough to show my gratitude. Big op unuself!

Damian, your continuing support and encouragement over the past 3 years has helped me through challenging times and pushed me to accomplish personal goals. You have shared so much about Comfort Castle, from local culture to hidden waterfalls. All of which contributed to this thesis.

Kari Henquinet and Greg Waite, thank you for the tremendous support, guidance, and inspiration for the past three years. I greatly appreciate your dedication to answer questions and provide insight on developing this thesis.

Mom and Dad, always my biggest fans and supporters. Always encouraging me to chase my dreams. Thank you for the support during my Peace Corps service and over the years. 


\section{List of Abbreviations}

ED: Enumeration District

GIS: Geographic Information Systems

JAD69: Jamaica Datum 1969

JMD: Jamaican dollars

JLP: Jamaica Labor Party

KML: Keyhole Markup Language

MP: Member of Parliament

PAR: Pressure and Release

PC: Parish Councilor

PDC: Parish Disaster Committee

PNP: People's National Party

ODPEM: Office of Disaster Preparedness and Emergency Management

WGS84: World Geodetic System 1984

ZCs: Zonal Committees 


\begin{abstract}
Jamaica experiences meteorological, hydrological, and geological natural hazards that can produce island-wide impacts. The island's exposure to multiple hazard types requires effective and sustainable mitigation and disaster risk management to lessen potential impacts, especially for vulnerable populations and communities. Comfort Castle, a small rural farming community, sits in the upper Rio Grande Valley of Portland parish and experiences earthquakes, landslides, hurricanes, heavy rainfall, and floods. Steep terrain and remoteness due to geographic location affect the community's geophysical vulnerability. Their social vulnerability results from a lack of employment, health, educational, and livelihood resources within the community. Together, geophysical, and social factors combine to create overall vulnerability of place and understanding these root causes leads to effective mitigation. In the case of Comfort Castle, limited accessibility is a common denominator among its root causes and exacerbates both geophysical and social vulnerability. Ethnographic and GIS analyses reveal the linking and influential connection between the community's accessibility and vulnerability of place. This study calls for existing vulnerability models like the Pressure and Release and Access models to place a significant emphasis on the role of accessibility as it relates to vulnerability. In doing so, mitigation measures can start at the deepest level and effectively lead to a reduction in vulnerability to natural hazards.
\end{abstract}




\section{Introduction}

Disasters are often falsely labeled as natural due to the geophysical nature of hazards that trigger such events. When viewed as "natural," it promotes the idea that disasters are beyond human control and immitigable. However, disasters are not natural; they result from hazards interacting with human populations and development (Faas \& Barrios, 2015). Within the very definition, it is evident that humans are intrinsic to the existence of disasters. The United Nations states, "disasters are a serious disruption of the functioning of a community or society involving widespread human, material, economic or environmental losses and impacts, which exceeds the ability of the affected community or society to cope with using its own resources," highlighting the human component and social causation of disasters. ${ }^{1}$ Geological, meteorological, hydrological, and biological natural hazards trigger disasters. Mitigating hazard impacts has focused mainly on technological and engineering efforts to reduce risk and vulnerability. Socioeconomic processes associated with risk and vulnerability are often ignored and result in unsustainable technical mitigative solutions, increasing vulnerability (McLaughlin \& Dietz, 2008; Zaman, 1999).

Given that humans are a fundamental component of disasters, it is therefore prudent to understand the causation of vulnerability for effective hazard mitigation. Vulnerability is, defined as, "the human tendency to suffer damage or loss." (Lavell \& Maskrey, 2014). Anthropologists, geographers, and other social scientists reveal that disasters do not simply occur, but are generated by social factors known as "roots causes" embedded in the history and development of societies interacting with natural hazard events (Cutter et al., 2000; Oliver-Smith, 1999; Wisner et al., 2004;). Their work acknowledges the critical human component of disasters and emphasizes the need to reduce vulnerability to mitigate hazards and reduce disaster risk. Human populations are vulnerable to hazards partially due to their physical location. However, considering other factors that contribute to vulnerability is prudent. Research indicates that social factors resulting in increased vulnerability are a significant contributing factor to a higher number of disasters worldwide (Wisner et al., 2004). It is imperative to look at how physical and social factors contribute to vulnerability; however, this viewpoint has become popular only recently.

During the 1970s, hazards and disasters were viewed as natural events that could not be mitigated and were not studied or analyzed through an anthropological lens (Fass $\&$ Barrios, 2015). Little was understood about human interactions with the environment and the impact of that relationship. With natural hazards viewed as uncontrollable, little effort was put into mitigation during this time. Over time, a shift in looking at vulnerability related to disasters took place (Oliver-Smith, 2016). Further into the 1980s, social scientists observed that disasters are not natural, and recognized resources and risk

\footnotetext{
${ }^{1}$ UNISDR Terminology on Disaster Risk Reduction, (2009). Source: http://www.unisdr.org/files/7817_UNISDRTerminologyEnglish.pdf
} 
are unequally distributed among communities who experience similar hazard events (Fass \& Barrios, 2015). This encouraged further application of anthropology to hazard mitigation after recognizing their social impacts. Despite these efforts to incorporate vulnerability and an anthropological perspective, people were still considered at risk to "natural disasters" from 1990-2000 (Oliver-Smith, 2016). During this time, the Pressure and Release Model" was developed and later published in 2004 (Oliver-Smith, 2016). The Pressure and Release Model focuses on vulnerability and the underlying root causes, dynamic pressures, and unsafe conditions combining with hazards to produce disasters, which current disaster risk reduction efforts draw from by trying to address the root causes (Wisner, 2004). Despite the advancement in research and evaluation of vulnerability, present-day efforts incorporate emergency management, preparedness, and recovery with little attention or effort towards addressing vulnerability and taking effective preventative measures (Oliver-Smith, 2016). Vulnerability is deeply rooted in the history and development of society, rendering it challenging to address. The importance of incorporating and implementing mitigation measures that address the root causes of vulnerability to natural hazards is obvious yet seldom practiced. This thesis underscores the importance of addressing the root causes of vulnerability to truly mitigate hazard impacts.

Since human vulnerability is essential to the occurrence of disasters, it is imperative to understand vulnerability comprehensively. Cutter et al. (2000) reveals the necessity to acknowledge the geophysical and social vulnerability that combine to create vulnerability of place. Their work suggests that vulnerability differs between communities, even if they experience similar hazards. Geographic location influences the geophysical and social characteristics that contribute to the level of vulnerability to which a community face.

\section{Vulnerability of Place}

Geophysical vulnerability focuses on the likelihood of exposure and the technological risk and is determined by assessing hazard potential, frequency, locational impacts, and geographic location characteristics (Cutter, 1996; Cutter et al., 2000). To an extent, addressing the physical characteristics that generate geophysical vulnerability is possible. For example, if an individual or community moves to a different geographic location, geophysical vulnerability to hazards can be reduced or potentially eliminated. However, physically moving may not always be a feasible or appropriate option. Although hazard potential, frequency, and locational impacts cannot change as hazards themself are natural phenomena, implementing mitigation measures to property and infrastructure can reduce hazard impacts. While geophysical characteristics are essential in determining the extent and patterning of human vulnerability, an overemphasis on these characteristics can neglect the social processes that influence vulnerability (McLaughlin \& Dietz, 2008). Therefore, it is pertinent to understand the causation of social vulnerability. 
Social vulnerability evaluates the likelihood of adverse consequences from disasters that inflict disruptions to daily life (Cutter, 1996). Socioeconomic factors contribute towards and exacerbate vulnerability. Access to resources, knowledge, and skills and political, social, and economic systems are factors that contribute to the vulnerability of individuals, families, and communities to disasters (Wisner et al., 2004). Such factors comprise of root causes, dynamic pressures, and unsafe conditions that create a progression of vulnerability and produces disasters when combined with hazards (Wisner et al., 2004). Human decisions and actions construct social vulnerability (Lavell \& Maskrey, 2014; Oliver-Smith, 2013). In theory, social factors can be altered, but are deeply rooted in society and arduous to address. Despite the challenge, implementing effective and sustainable mitigation measures to diminish root causes and reduce social vulnerability is important.

The combination and interaction between geophysical and social vulnerability generate vulnerability of place (Cutter et al., 2000). Vulnerability of place acknowledges how geographic location influences the geophysical and social aspects of vulnerability to natural hazards. Limited physical accessibility can hinder localized mitigation efforts, exacerbating hazard impacts through delayed or limited response actions, increasing geophysical vulnerability (McLaughlin \& Dietz, 2008). Social vulnerability increases when the exchange of goods, services, and resources from within and outside of communities becomes challenging to access. The ability to access such goods, services, and resources builds capacity and increases resiliency to natural hazards, diminishing vulnerability (Wisner et al., 2004). Alleviating geophysical and social vulnerability effectively mitigates hazards.

\section{Accessibility}

Human vulnerability is caused by a lack of resources, information, knowledge, and access to political power and representation (Cutter et al., 2000; Wisner et al., 2004). Resource availability and opportunities to access political advocacy correlate with community development. As communities develop, hazard vulnerability can decrease, further increasing the community's capacity and resiliency to natural hazards. For example, access to economic and social benefits to reduce vulnerability relies upon adequate transportation to avoid disruptions that inhibit road network functionality (Taylor et al., 2006).

Deficient transportation infrastructure impedes socio-economic development, particularly in developing countries and rural areas where "network accessibility is low and local networks are missing roads or in poor condition (Olsson, 2006; WBCSD, 2007)" (Olsson, 2009). Poor conditions, geographic location, and limited availability of alternative routes produce inadequate road systems. While local resources are available in many rural communities to sustain livelihoods, resources such as health care, education, and additional employment are often only available outside the community. The ability of individuals to access these resources is vital for stimulating rural economic growth and the welfare of people to decrease hazard vulnerability (Cervero, 1990; Nyberg \& 
Johnansson, 2013). Instituting road and transportation improvements are critical prerequisites for enhancing accessibility and living conditions by accessing additional services and resources (Cervero, 1990). Transport is one of many critical services needed for development (Leinbach, 1994). Road improvements can benefit communities in several ways. In rural areas, local markets provide nearby communities with improved access to resources, economic development, new income-earning opportunities, educational benefits, and social interactions (Mu \& Van De Walle, 2001). Road investments can stimulate economic growth, especially for rural areas, which in return increases capacity and resiliency to reduce vulnerability to natural hazards (Cervero, 1990).

Community development and economic growth are not inherent results of improved road infrastructure as they depend on different contextual factors at the community, regional, and national levels (Olsson, 2009; Windle \& Cramb, 1997). Travel to city centers relies on availability and adequacy of public transportation services or personal vehicles. Relationships among rural community members, social and economic development agencies, and political representatives in urban centers is a critical component. If such relationships are non-existent, services provided by these agencies and political representatives will not reach or benefit rural communities. Amending educational deficiencies if they exist, within rural communities, is also required. In some instances, improved roads and accessibility leads to threat and impoverishment when outsiders take advantage of resources in rural areas (Wilson, 2004). Although a better road does not automatically result in development, increased access is a critical first step in stimulating rural development (Windle \& Cramb, 1997). Careful evaluation on the outcomes of road improvements is needed before implementation.

\section{Accessibility and Vulnerability of Place}

Economic growth and community development hindered by road quality, restrictive geographic locations, and limited network connectivity showcase the relationship between accessibility-related issues and vulnerability of place. Cervero (1990) examines the effects of accessibility on rural farming communities in Sumatra and describes accessibility as access to opportunities that are influenced by road quality, frequency of bus services, and proximity to city centers. However, this definition should also include factors such as the number of access points, available alternative routes, and physical location. Wisner et al. (2004) defines access as "the ability of an individual, family, group, class or community to use resources which are directly required to secure a livelihood in normal, pre-disaster times, and their ability to adapt to new and threatening situations," (pg. 94) In this thesis, accessibility encompasses the availability of opportunities to access goods, resources, and services to reduce vulnerability to natural hazards. Characteristics such as road quality, public transportation services, proximity to market towns, number of access points, alternative routes, and physical location impact physical accessibility. 
The Pressure and Release model illustrates root causes, including limited access to power, resources, structures, and political and economic systems that generate dynamic pressures and unsafe conditions leading to vulnerability (Wisner et al., 2004). When hazards impact vulnerable populations, disasters arise. The Access Model further demonstrates "how the amount of 'access' that people have to the capabilities, assets, and livelihood opportunities that will enable them (or not) to reduce their vulnerability and avoid disaster." (Wisner et al., 2004, pg. 88). While this model addresses what generates root causes in the PAR model, it does not help us consider what factors reduce physical accessibility and restrict access to resources, services, and opportunities to reduce vulnerability. One reason may be that many factors affect accessibility, and it would be difficult to depict with a visual representation. Although true, road infrastructure is also a common denominator, particularly for rural areas. Physical barriers from poor road infrastructure can lead to negative mentalities, ideas, attitudes, and restricted assets, resources, and opportunities that further reduce accessibility and increase vulnerability of place.

\section{Overview}

This thesis examines the relationship between accessibility and vulnerability of place in Comfort Castle, Jamaica, with natural hazards. Results from ethnographic and GIS analyses reveal the geophysical and social vulnerabilities facing the community and point to geographic location and the road as central contributors to vulnerability. Limited accessibility of Comfort Castle further increases its vulnerability due to the Rio Grande Valley Road's quality. Throughout this paper, accessibility relates to available opportunities and incorporates factors such as physical location, distance to markets, road quality, and number and type of entry points to Comfort Castle (Cervero, 1990). All the characteristics of accessibility impact the availability of goods, services, and resources that promote development and are essential for decreasing vulnerability to natural hazards and poverty.

The objective is to demonstrate both the geophysical and social aspects of accessibility and show how accessibility is connected to vulnerability and influenced by geographic features. Furthermore, resolving accessibility limitations can reduce overall vulnerability of place.

While existing vulnerability frameworks incorporate and acknowledge accessibility, it is seldom the focal point when identifying and assessing its causation (Cutter et al., 2000; Wisner et al., 2004). A deep dive into Comfort Castle's vulnerability through data analysis reveals accessibility as a focal point of causation and which aspects of accessibility are most important for reducing the community's vulnerability. The researcher postulates that for Comfort Castle, Jamaica, amending accessibility issues reduces vulnerability of place to natural hazards generated by roots causes. While considering all geophysical and social factors is essential to reduce vulnerability, focusing on accessibility as the common denominator, for this location, mitigates hazard impacts starting at the deepest level 
The next section (Section 2) provides background and contextual information about Jamaica and Comfort Castle, the study location. Section 3 follows with the methodologies used to collect qualitative data through ethnography and quantitative data using Geographic Information Systems (GIS). Section 4 presents the results from ethnographic and GIS analyses in subsections 4.1 and 4.2. 


\section{Background}

\subsection{Jamaica:}

The island of Jamaica, part of the West Indies archipelago in the Caribbean Sea, is located south of the United States and north of South America. In area, Jamaica is the third-largest island in the Caribbean at 4,243 sq. miles (10,991 sq. kilometers). ${ }^{2}$ Jamaica consists of three counties, Cornwall, Middlesex, and Surrey, subdivided into the 14 parishes shown in figure 2.1.1. As of 2018, Jamaica is home to 2.7 million people, with most of the population located in the urban areas of Kingston and Montego Bay. ${ }^{3}$

Although, poverty is more prevalent in rural areas with a rate of $21.5 \%$ compared to a 9.9\% rate in urban areas (Carby et al., 2012).

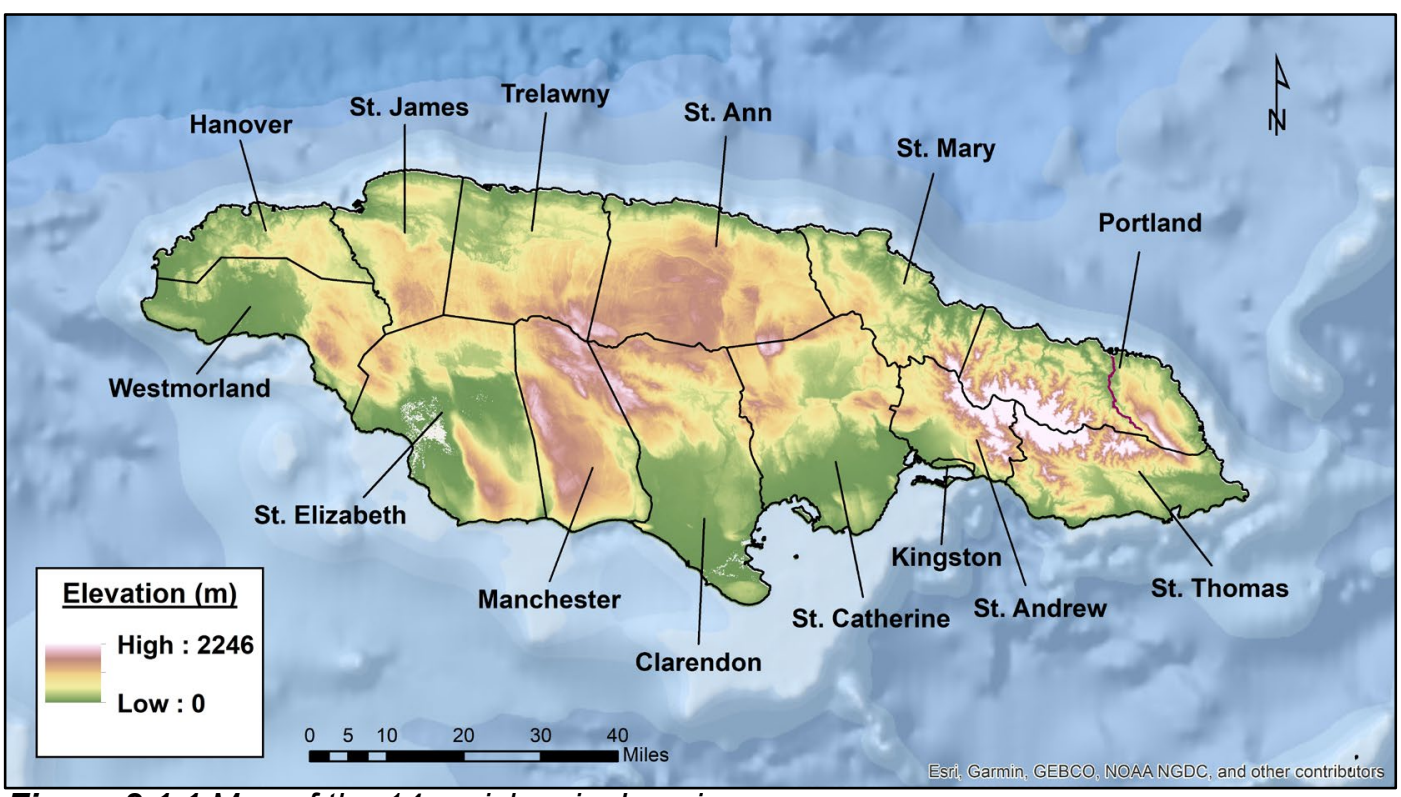

Figure 2.1.1 Map of the 14 parishes in Jamaica

Jamaica was colonized by the Spanish from 1494-1655 and later by the British from 1655-1962. Throughout Spanish and British colonization, an estimated 600,000 enslaved Africans were brought to Jamaica through the transatlantic slave trade from 1533 to 1807 when slavery was abolished. ${ }^{4}$ However, African slaves were not truly free in Jamaica until August $1^{\text {st }}, 1834$, known as Emancipation Day. Jamaica later received its independence from British rule in 1962, establishing a constitutional monarch with a parliamentary government. ${ }^{5}$ The prime minister is the head of government and appointed by the leading political party from a general election. The two parties that dominate the

\footnotetext{
${ }^{2}$ World factbook. Source: https://www.cia.gov/library/publications/the-world-factbook/geos/jm.html

${ }^{3}$ Statistical Institute of Jamaica. Source: https://statinja.gov.jm/Demo_SocialStats/PopulationStats.aspx

${ }^{4}$ National Library of Jamaica. Source: https://nlj.gov.jm/slave-trade/

${ }^{5}$ Encyclopedia Britannica. Source: https://www.britannica.com/place/Jamaica/Government-and-society
} 
political system are the Jamaican Labor Party (JLP) and People's National Party (PNP). General elections occur every five years to determine the leading political party. The elected leading party then appoints the Prime Minister. 63 Members of Parliament (MPs) are elected representatives of constituencies that make up each parish. Each parish has a different number of constituencies. MPs are not limited to terms; they remain in office if they are re-elected. Government at the parish level is managed by a Parish Council comprised of Parish Councilors (PCs) and is the lowest local authority of governance in Jamaica. Each Enumeration District within the parish is represented by a PC.

While English is Jamaica's official language, most speak Jamaican Patwa, often the first language for many nationals. It is spoken widely throughout the county with differing regional dialects and vernacular. Developed by African slaves in Jamaica, Patwa incorporates a mixture of British English and West African vocabulary. During slavery, individuals who escaped into the rugged and remote interior of the island and formed settlements are known as Maroons. One settlement called Nanny Town formed in the Blue Mountains and was home to the Windward Maroons (Kopytoff, 1978). Today, many residents of the communities in the Rio Grande Valley, including Comfort Castle, Ginger House, and Mill Bank, are descendants of the Windward Maroons.

Jamaica's topography consists of coastal and inland plains, limestone features and high interior mountain ranges (Carby et al., 2012). The John Crow and Blue Mountain ranges are situated in the eastern part of the island. Blue mountain peak, of the Blue Mountain range, is the highest point in Jamaica, reaching 2,256 meters above sea level (Bhalai, 2010). Over one half of the land has slopes greater than 20 degrees, increasing vulnerability to erosion and mass wasting (Ishemo et al., 2006). Karst topography dominates the western region of the island and is locally known as "cockpit country."

In general, Jamaica has a hot and humid tropical climate. However, regional climate is dependent upon geographic location and juxtaposition to the mountain ranges. For example, the Upper Rio Grande Valley in Portland, situated between the Blue and the John Crow Mountains, is classified as a rainforest with high annual rainfall and lush green vegetation. In contrast, parts of southern St. Catherine have an arid climate conducive for a desert climate and vegetation such as cacti and agave. Rainfall is bimodal and peaks during October and May, with the highest amount of annual rainfall occurring in the eastern parishes of Portland and St. Thomas. (Carby et al., 2012; Nkemdirim, 1979). Climate change will likely affect climate-related natural hazards in Jamaica. The frequency of flooding events has increased over the past 25-30 years resulting from tropical depressions, tropical storms, and hurricanes (Carby et al., 2012).

The Office of Disaster Preparedness and Emergency Management (ODPEM) established in 1979 after significant flooding in Western Jamaica (UNDP, 2009). As a government-affiliated office, ODPEM promotes awareness, facilitates hazard and vulnerability assessments, instills preparedness and mitigation measures, and implements policies and programs to reduce disaster risk. ODPEM operates at the national, regional, parish, and community levels to fulfill its mission to decentralize disaster risk 
management. At the national level, ODPEM works alongside the Ministry of Local Government, Ministry of Health, Jamaica Defense Force, Jamaica Constabulary Force, and other non-governmental actors to form the National Disaster Committee (Osei, P.D., 2007). The prime minister heads this committee that meets annually to discuss activities and management of disaster risk for the entire nation. ${ }^{6}$ Four regional officers work throughout the country as liaisons between the parishes and ODPEM at the national level. All 14 parishes have a Parish Disaster Committee (PDC) to execute disaster risk management at the parish level. While the PDC receives allocated funds from the national government, its budget is not autonomous, often limiting the committee's functionality (Blackburn, 2014). Implemented at the community level, Zonal Committees (ZCs) are volunteer-based and manages disaster risk at the lower governmental level. OPDEM's efforts to decentralize disaster risk management are evident through the implementation of PDCs and community ZCs, again their success is limited by funding constraints (Blackburn, 2014).

Over $96 \%$ of Jamaica's population is at risk from two or more hazards, making the island the third most exposed country to multiple hazards. ${ }^{7}$ Natural hazards, including hurricanes, earthquakes, flooding, tsunamis, droughts, storm surge, and, landslides affect Jamaica. The island's geographic location within Caribbean Sea and an active seismic zone increase its vulnerability to hazards such as hurricanes and earthquakes (Carby et al., 2012). Five active fault zones intersect Jamaica, including the Plantain Garden Fault Zone that triggered the 2010 Haiti earthquake. ${ }^{8}$ Hurricanes bring a yearly threat as the season occurs from June to November, annually (Osei, P. D., 2007). Increased rainfall and wind speeds can result from the fringes of storm systems passing near Jamaica. Landslides and flooding are often secondary hazards and induced by hurricanes, tropical troughs or depressions, and heavy, seasonal rainfall as the primary hazards. Historic disasters in Jamaica include the 19627.5 magnitude Port Royal Earthquake, 1988 category 3 Hurricane Gilbert, and 2004 category 4 Hurricane Ivan (Carby et al., 2012; Osei, 2007).

Geographic location and social factors increase Jamaica's vulnerability to natural hazards and further exacerbates the vulnerability of specific populations. Children, youthat-risk, the elderly, persons with disabilities, women, and low-income families are considered vulnerable groups as well as people living in rural, coastal, and low-lying areas (Carby et al., 2012). ${ }^{9}$ A higher level of poverty in some regions may further increase vulnerability to these segments of the population.

Social factors such as financial debt, health status, climate change, and weak building code enforcement also influence Jamaica's vulnerability (UNDP, 2009). Impacts of

\footnotetext{
${ }^{6}$ Information gathered from interview with a member of the Portland Parish Disaster Committee.

${ }^{7}$ Global Facility for Disaster Reduction and Recovery. Source: https://www.gfdrr.org/en/jamaica.

${ }^{8}$ Global Facility for Disaster Reduction and Recovery. Source: https://www.gfdrr.org/en/jamaica

${ }^{9}$ In the Jamaican context, youth-at-risk are unemployed adolescents or young adults without a high school education.
} 
natural hazard events have contributed to Jamaica's national debt. Structural adjustment practices implemented during the 1980s to reduce national debt and inflation rates partially attribute to prior hurricane damages endured by Jamaica (Wisner et al., 2004). The government reduced health, education, and other public program budgets as well as disaster preparedness and mitigation measures. At this time, the vulnerability of Jamaican residents increased significantly, potentially intensifying the impacts later felt from Hurricane Gilbert and Hurricane Hugo in 1989. Even in recent years, Jamaica's debt repayment still consumes a significant portion of the government's budget. Between 2007 and 2008 , debt payment totaled $54 \%$ of the total budget compared to $12 \%$ for education, $7 \%$ for national security, and 5\% for health. (Carby et al., 2012; Planning Institute of Jamaica, 2010). A reduction in socioeconomic resources increased vulnerability for a segment of Jamaica's population to natural hazards (Wisner et al., 2004).

Jamaican roads are vulnerable to natural hazards due to physical, geographic, and tectonic features (Carby \& Ahmad, 1995). Damage to roads from hazard impacts further increases vulnerability for communities and socioeconomic functions that rely on them. Impacts from Hurricane Gilbert in 1988, a two-day period of heavy rainfall in 1991, and Tropical Storm Gordon in 1994 resulted in significant damage to road infrastructure (Carby \& Ahman, 1995). Roads are often blocked and damaged from landslides triggered by high amounts of rainfall and slope failure, delaying emergency evacuations, assistance, and aid delivery. Community members, as well as local and national government officials experience and acknowledge this issue. Landslides also cause damage to culverts and retaining walls requiring additional repairs beyond debris removal. Geographic location of roads also plays a significant role in vulnerability. Roads in the eastern parishes wind through mountainous terrain and often cut into steep slopes (Carby \& Ahman, 1995). Heavy rains associated with a hurricane system in 2001 caused damage to 440 roads island-wide (UNDP, 2009).

\subsection{Study Location: Comfort Castle, Jamaica}

Comfort Castle is located in the Upper Rio Grande Valley of Portland, Jamaica (figure 2.2.1), surrounded by the Blue Mountains to the west and the John Crow Mountains to the east. Three communities, including Comfort Castle, Mill Bank to the south, and Ginger House to the north, create the Comfort Castle Enumeration District (ED), shown in figure 2.2.2. While they are three separate communities, many residents consider them as one since all three shape the ED and rely upon each other for local employment, social, educational, and livelihood resources. Additionally, members from each community vote to elect one parish councilor who represents the ED at the parish level of government. 


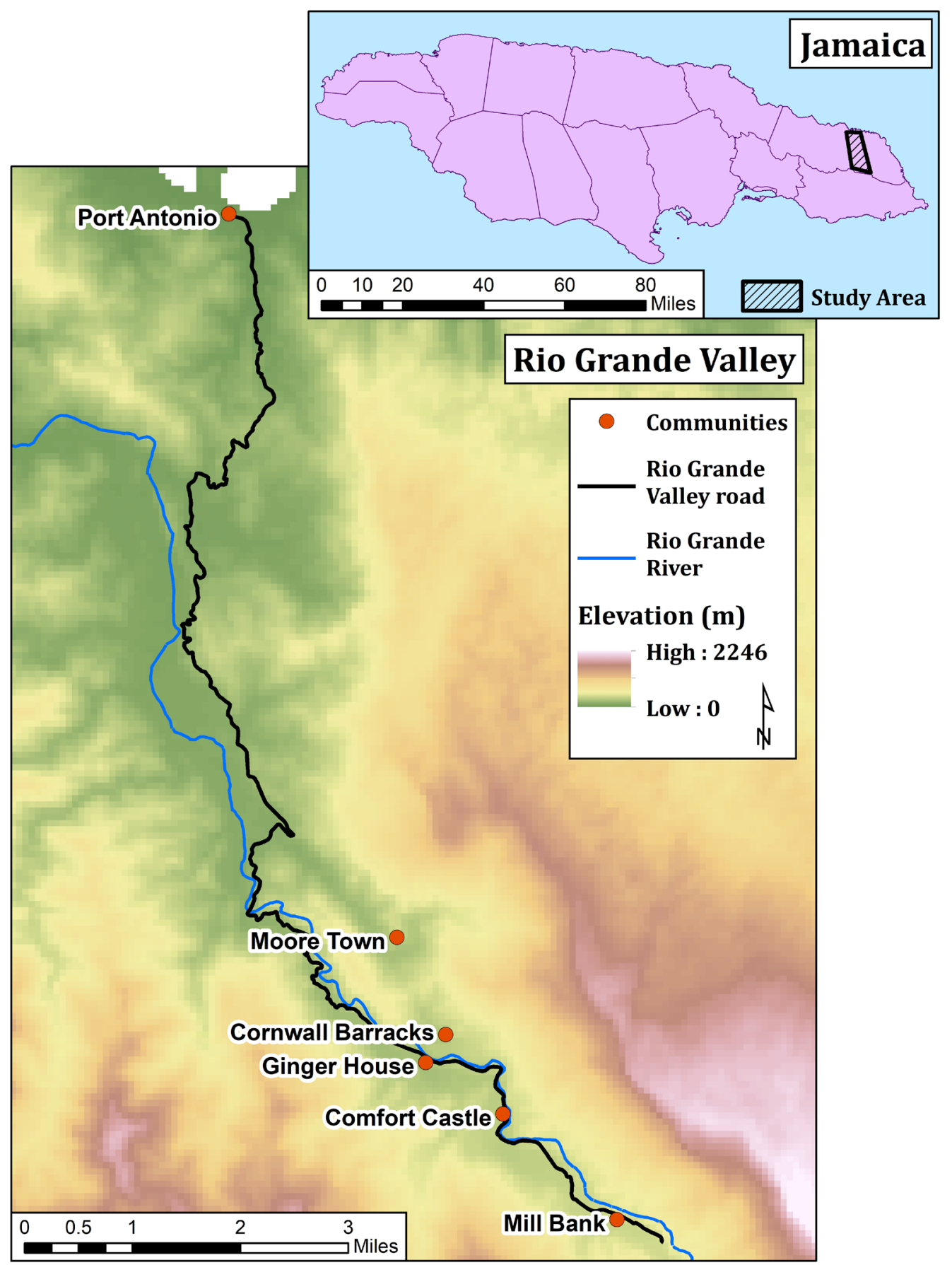

Figure 2.2.1. Map of study location and referenced locations throughout this thesis. 


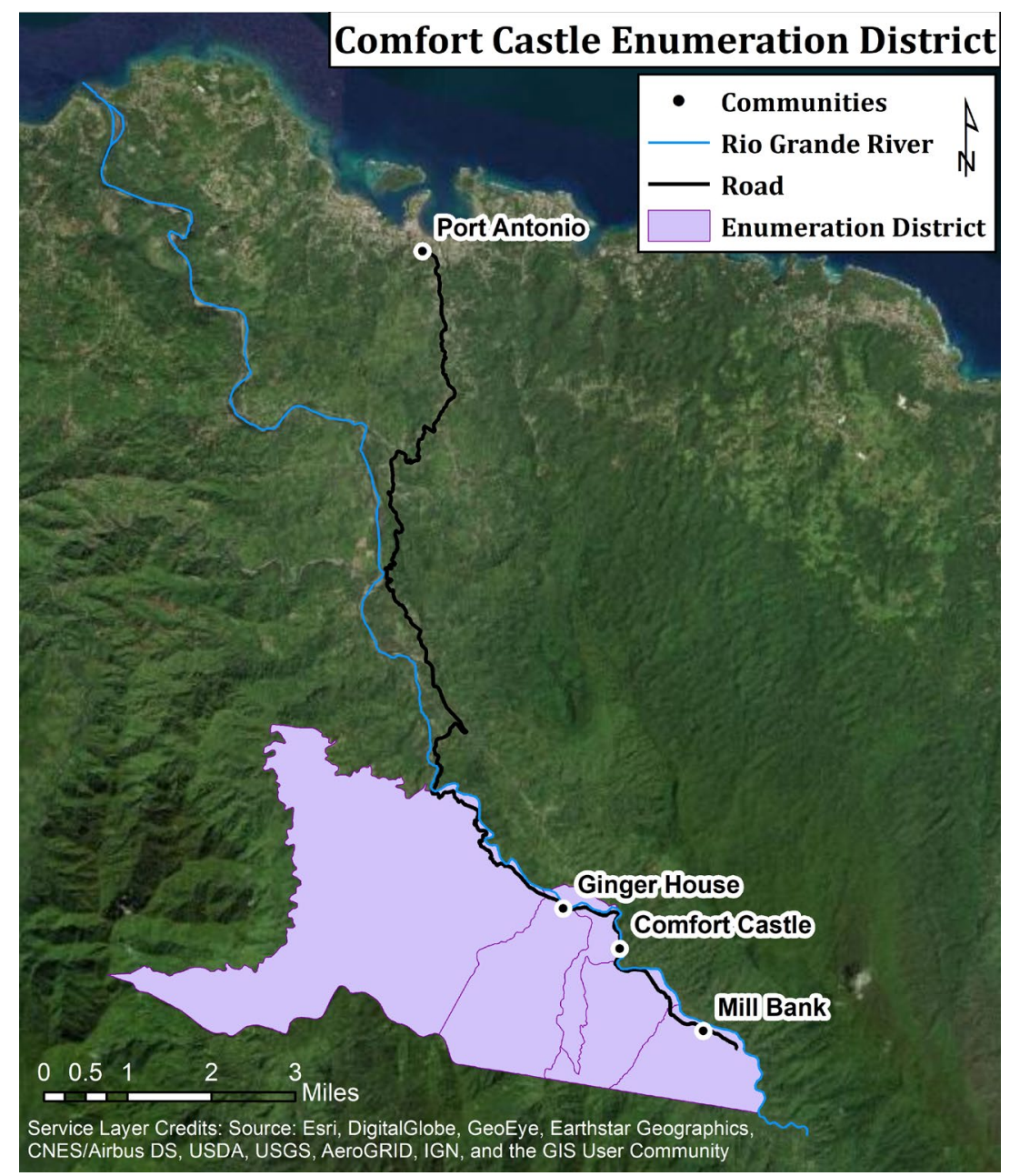

Figure 2.2.2. The Comfort Castle Enumeration District consists of Ginger House, Comfort Castle, and Mill Bank.

As a whole, Portland is a rural, predominantly agricultural parish with high poverty levels (Ishemo et al., 2006; Meikle, 1998; Blackburn, 2014). Comfort Castle ED consists of roughly 1,980 with $22 \%$ of the population living in poverty (Planning Institute of Jamaica \& Statistical Institute of Jamaica, 2019). Most community members in Comfort Castle are self-employed farmers who either sell their produce for income or use it for subsistence. Common agricultural products include dasheen, coffee, bananas, yams, peppers, pumpkin, and pak choi (bok choy). Farmers also raise livestock such as cattle, goats, chicken, and pigs. Local shops, the primary and basic school, and police station also provide employment opportunities. However, the number of positions is limited, and a single family typically manages one shop. Men find opportunities as skilled laborers undertaking plumbing, electrical, carpentry, masonry, and construction work to generate income. Women tend to be shopkeepers, seamstresses, or hairdressers. While a variety of employment opportunities are available, few can generate adequate income. The small size and population of Comfort Castle limit the number of skilled workers or shopkeepers who can participate in the local economy. 
Port Antonio is the capital of Portland and the nearest shopping town to Comfort Castle. Community members must travel 15 miles by personal vehicle or public transportation to access economic, educational, social, and livelihood resources outside of Comfort Castle and the surrounding area. All students must travel to Port Antonio or farther to attend high school when they reach grade 7. The Comfort Castle Primary and Junior High School provides education for students in grades 1-6 while the Comfort Castle Infant Department supports pre-kindergarten and kindergarten students. The schools comprise of children from Comfort Castle, Ginger House, Mill Bank, and Cornwall Barracks, a community across the Rio Grande River.

History of the Upper Rio Grande Valley stems back to the 1680s when Maroons established settlements in remote wooded and mountainous areas (Kopytoff, 1978). Jamaican maroons were slaves who escaped from plantations during Spanish and British colonization. Two bands formed known as the Windward and Leeward Maroons. The Windward Maroons settled in Nanny Town, a remote location deep within the Blue Mountains in Portland. ${ }^{10}$ After the Emancipation Act in 1834, Maroons eventually became free persons and migrated to more accessible locations. Over time, Maroons formed settlements that are still occupied today, including Mill Bank, Comfort Castle, and Ginger House. ${ }^{11}$ Maroons also settled in Moore Town, a nationally recognized Maroon community governed by a colonel. ${ }^{12}$ Comfort Castle's culture is deeply tied to Maroon culture, as many residents are descendants of Maroons. Today, Maroon heritage and culture are celebrated through annual festivals, traditional ceremonies, and school curricula and heritage days.

Situated among mountainous terrain along a winding river and on a dirt road, Jamaicans consider Comfort Castle as, "back a bush." 13 The community is also viewed as remote or secluded. Remoteness of the community restricts local development and access to resources located in city centers (Windle \& Cramb, 1997). Only one road referred to as the Rio Grande Valley Road, provides vehicular access from Port Antonio, 15 miles away, to the area. When the road reaches a few miles south of Mill Bank it turns into a walking path. Essentially, the Rio Grande Valley Road is the only way in and out of the community by vehicle. The Ginger House Swinging Bridge provides walking access between communities on both sides of the Rio Grande River. Residents utilize the walking bridge to socialize and for economic and educational purposes. At times, residents from Comfort Castle will cross the river to Cornwall Barracks to access additional public transportation services.

\footnotetext{
${ }^{10}$ National Library of Jamaica. Source: https://www.nlj.gov.jm/historynotes/History $\% 20$ of $\% 20$ Portland $\% 20$ Final.pdf

${ }^{11}$ Based on anecdotes from participant observation in Comfort Castle

${ }^{12}$ National Library of Jamaica. Source: https://www.nlj.gov.jm/historynotes/History $\% 20$ of $\% 20$ Portland $\% 20$ Final.pdf

13 "Back a bush" is a Jamaican Patwa phrase meaning deep rural or country area.
} 
The Rio Grande River is the central river basin for the Rio Grande Valley and covers one-third of the parish (Davis-Morrison \& Barker, 1997). Periods of heavy rainfall can increase the river level substantially and trigger local floods. Discharge of the Rio Grande River is highly variable and prone to flooding (Nkemdirim, 1979). The rainy season in Comfort Castle lasts from September to February (from ethnographic data). Typically, periods of intense rainfall occur from October to January. Rainy days and short periods of rainfall are also common during the dry season from March to August. On average, 500 $\mathrm{cm}$ (196 in.) of rain falls annually in eastern Jamaica, more than anywhere else on the island (Bhalai, 2007). Annual rainfall averages are highest in the northeastern portion of Jamaica (Nkemdirim, 1979).

Similar to national hazards, landslides, earthquakes, hurricanes, and flooding, are common in Comfort Castle as well. Many community members do not view heavy rainfall as a hazard despite periods of rainfall producing landslides and flooding events. Locals have adapted their livelihoods to withstand and accommodate for frequent rainfall and high-intensity events. For instance, farmers take advantage by planting crops such as dasheen and yams that thrive in wet climates. However, some due acknowledge it as a hazard when rainfall amount are exceptionally high. Localized hazards include landslides and flooding, while hurricanes and earthquakes are typical hazards that affect regions in Jamaica or the entire country.

Comfort Castle has experienced significant impacts from local and national hazards, including the Mill Bank Landslide (1937) and Friday Landslides (2011), Hurricane Gilbert (1988), and Upper Rio Grande flooding in 2016 (Bhalai, 2010; Harris 2002). The Mill Bank landslide dammed the Rio Grande River and blocked off the community for an extended period (Bhalai, 2007). Hurricane Gilbert impacted the entire island. Infrastructure, roads, buildings, homes and agricultural fields were damaged, disrupting livelihoods and forcing many Jamaicans to start over. The Friday Landslide in 2011 blocked the Rio Grande Valley Road between Comfort Castle and Ginger House forcing residents to walk a mile up through the hills to access Comfort Castle and Mill Bank. ${ }^{14}$ In 2016, high amounts of rainfall increased the Rio Grande River level drastically, and debris in the river demolished the Ginger House Swinging Bridge. ${ }^{15}$ Residents did not have a bridge for three years to safely cross the river, reducing access to agricultural fields for farmers, employment opportunities for skilled laborers, schools for students, and social events for community members. Not only did these events damage local infrastructure, but they also disrupted daily life and resulted in significant socioeconomic impacts. Together with geophysical and social vulnerability, these hazards created disasters.

\footnotetext{
${ }^{14}$ The Gleaner. Source: http://jamaica-gleaner.com/gleaner/20110210/news/news2.html

${ }^{15}$ Based on anecdotes from participant observation with community members.
} 


\subsubsection{Landslide Hazards}

The local geology, steep slopes, and heavy rainfall make the area susceptible to landslide hazards, influencing the frequency of events in Comfort Castle(Ahman, 1998; Ishemo et al., 2006). Many slopes in the Rio Grande Valley exceed 30 degrees and are prone to erosion and mass wasting (Davis-Morrison \& Barker, 1997). Frequent rainfall throughout the year keeps soil moisture at or near saturation, decreasing slope stability (Nkemdirim, 1979). Unfortunately, landslide impacts worsen the geophysical vulnerability of the community. Agricultural fields, houses, and communities are often located on unstable hillside slopes or in floodplains, leaving them vulnerable to landslides and floods (Ishemo, 2006). Landslides often take place along the Rio Grande Valley Road and can restrict or block access to Comfort Castle as well as Ginger House and Mill Bank.

Suresh Bhalai conducted in depth research on landslide susceptibility in Portland, Jamaica. Justification for his research lies in the necessity to study this portion of the island due to the frequent occurrence of rainfall and seismic event triggered landslides (Bhalai, 2010). Statistical methods, remote sensing analysis, and field surveys shape Bhalai's landslide susceptibility model. Below are the steps taken to create the susceptibility model:

i) Remote sensing interpretation and review of records of landslide occurrences

ii) Data collection (topographic and geologic causative factors)

iii) Field surveys and confirmation checks

iv) Statistical analysis and generation of susceptibility model (including testing)

v) Compilation of supporting guidelines for using the susceptibility model

Monochromatic and panchromatic remote sensing aerial imagery are used to create a landslide inventory. Data is collected on topographic features including elevation, slope gradient, and slope aspect, as well as geologic features including rock type and faults. These features are considered causative factors for landslide and are divided into classes and ranges to assess their correlation with landslide events. Bivariate statistical analysis determines the correlation between the causative factors and landslide events and assigns a weighted numeric value to the different classes based on their influence on landslide occurrence.

The model reveals five levels of landslide susceptibility within the parish of Portland. The levels of susceptibility include: (1) negligible to low; (2) moderate; (3) moderately high; (4) high; (5) very high. Slopes along the Rio Grande Valley Road have a very high landslide susceptibility. Areas of higher susceptibility are common in Blue and John Crow Mountain regions, shown in figure 2.2.1.1. 


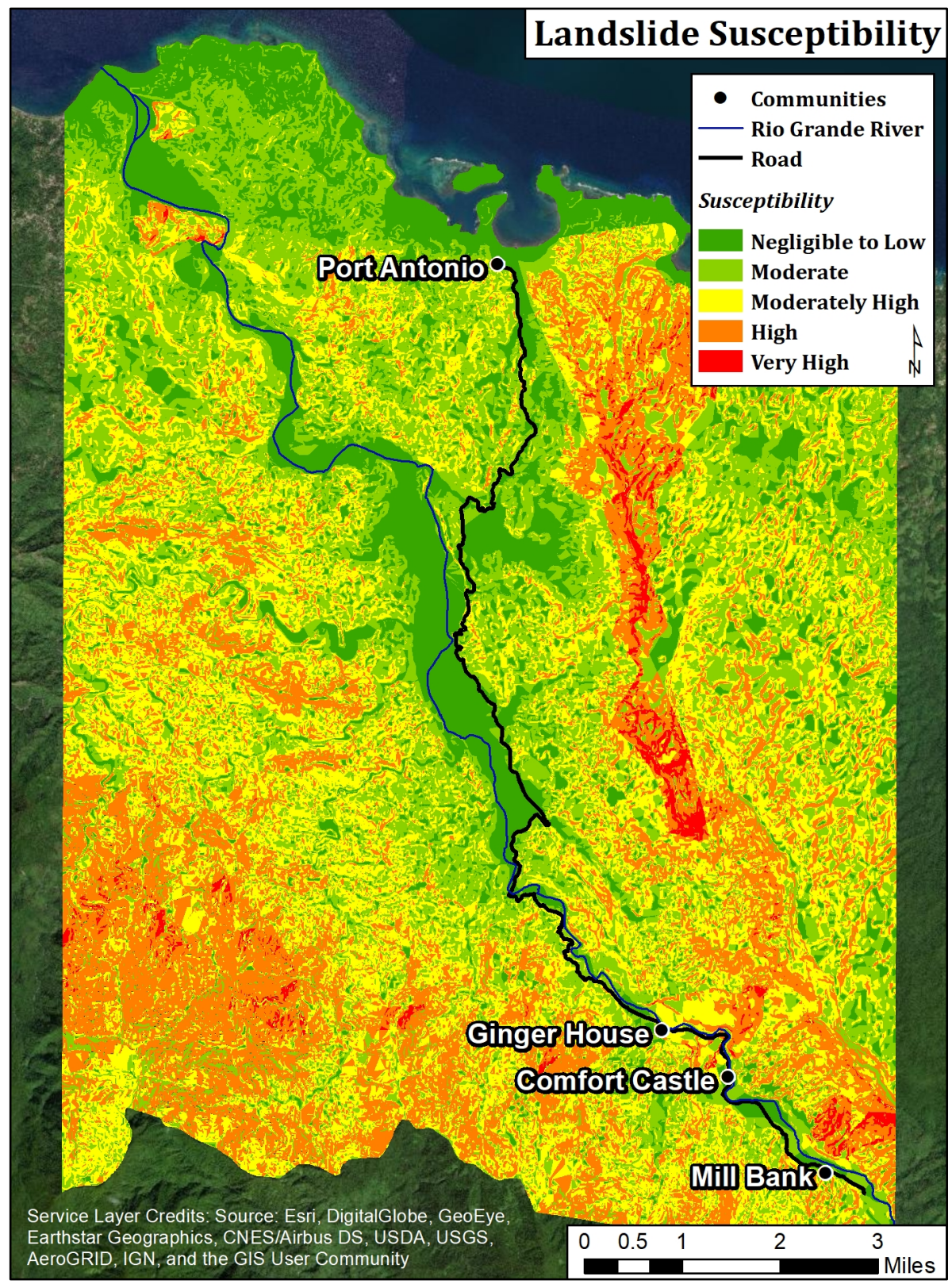

Figure 2.2.1.1. Landslide susceptibility and zonation in Portland produced using GIS data from the Jamaica Mines and Geology Division from Suresh Bhalai's research.

Friday, a location along the Rio Grande Valley Road between Comfort Castle and Ginger House, is identified as having a high to very high level of susceptibility (Bhalai, 2010). Here, the road is exposed to a steep, unstable hillside on one side and a 91-meter drop to the Rio Grande River on the other side. A retaining wall was installed in 2011 after having rainfall washed out the road and triggered a landslide. ${ }^{16}$ The hillside consists

\footnotetext{
${ }^{16}$ The Gleaner. Source: http://jamaica-gleaner.com/gleaner/20110210/news/news2.html
} 
of colluvium (debris of volcanic rock and limestone) overlying shale bedding dipping towards the road, encouraging slope failure (Bhalai, 2007; Bhalai 2010). Since 2000, Friday has been actively retreating and creating several hazardous events along the road (Bhalai, 2010). Landslides are likely to occur after periods of heavy rainfall and often obstruct the road. Most of the Rio Grande Valley Road is narrow and single lane, restricted between steep hillsides and plummeting cliffs.

In Comfort Castle, the Rio Grande Valley Road provides the only vehicular access to outside resources that aid in local development and support livelihoods. While a valuable asset, the road is vulnerable to hazard impacts, particularly landslides. In January of 1988, two days of heavy rainfall produced triggered about 270 landslides across Portland, damaging 1.27 kilometers of roads parish-wide, including 806 meters of road in the Rio Grande Valley (Bhalai, 2007; Harris 2002). Several breakaways triggered by landslides in 2005, reducing the Rio Grande Valley Road to a single lane in several locations (Bhalai, 2007). Residents recollect the Friday landslide in 2011, blocking the road for a significant amount of time and greatly reducing accessibility to Comfort Castle and Mill Bank. According to community members, landslide hazards affect the road most frequently.

Residents of Ginger House, Comfort Castle, and Mill Bank depend on the Rio Grande Valley Road to fulfill everyday needs and maintain their livelihoods. Shops, the Comfort Castle Primary and Junior High School and Infant Department, Mill Bank Police Station, and churches are the only available resources in the Comfort Castle ED. Community members must travel to Port Antonio to pay bills, access banking accounts, send or receive mail, and buy farming equipment, hardware supplies, and household goods. The nearest hospital and health clinics and governmental agency offices are also located in Port Antonio. While only 15 miles away, one-way travel to Port Antonio takes one hour in good weather. Many residents rely on public transportation to travel; few have personal vehicles. Four buses seating 10-18 passengers travel to Port Antonio daily from morning until evening, Monday through Saturday. Only one bus runs late into the night, after dark. Public transportation is not available on Sundays and is less reliable during the summer holiday when school is out of session.

Disasters occur in Comfort Castle when hazard impacts interact with the community's social vulnerabilities. Factors such as limited access, restricted finances, a lack of resources, and an absence of political power and representation increase the community's vulnerability of place to disasters. While locals have adapted to accommodate for heavy rainfall, hazards such as hurricanes, landslides, and earthquakes are challenging to mitigate and prepare for. Local knowledge and experience with past events help with preparing for, responding to, recovering from, and mitigating disasters. However, Comfort Castle's limited accessibility hinders the degree to which capacity and resiliency can increase in order to reduce the community's vulnerability of place. 


\section{Methods}

This thesis consists of ethnographic and geologic data gathered while serving as a Peace Corps volunteer in Comfort Castle, Jamaica. The researcher is a master's International Student (PCMI) in the Geology Department at Michigan Technological University. Both qualitative and quantitative data were utilized in this study. Ethnographic, or qualitative data (semi-formal interviews, focus groups, participatory mapping, and participant observation) coupled with quantitative data (landslide susceptibility, geologic, and population data) were collected to understand local perceptions of natural hazards and their impacts. Social vulnerabilities and perceptions of natural hazards were captured with ethnographic data. Geologic, landslide susceptibility and population data evaluate the geophysical vulnerability of natural hazards in the community.

\subsection{Ethnographic Analysis}

During the researcher's Peace Corps service, Comfort Castle community members provided ethnographic data by sharing their perceptions of natural hazards and how they impact the community. Participatory mapping, semi-formal interviews, focus group sessions, participant observation, and field notes were used to collect data. The importance of ethnographic data lies in the necessity of understanding how natural hazards become disasters when they impact people. Therefore, we need to understand the complex relationship between people and natural hazards by understanding local knowledge, experiences, and the history of natural hazards.

IRB human subjects research approval was required to gather ethnographic data. The project received IRB approval before collecting data over 17 months from November 2017 to April 2019. Additional interviews focusing on the personal experiences of community members with Rio Grande Valley Road were facilitated over three weeks from December 2019 to January 2020. Building rapport with Comfort Castle community members was essential before collecting data. Interacting with community members daily over 24 months allowed the researcher to become more familiar with daily life and establish personal relationships. Social gatherings such as meetings, church services, celebrations, working at the school, and even sharing a taxi ride provided many opportunities for participant observation and to build rapport. Such opportunities allowed the researcher to understand the intricacies of life in Comfort Castle, Jamaica. As a result, participants felt comfortable in sharing their thoughts and experiences, providing a deeper understanding of the data collected to the researcher.

Field notes, on participant observations about general day-to-day of the community, began November of 2017. Notes entail information from observations on gender, social interaction, government, and religion by attending social functions and community meetings to participate in conversations and listen to community members 
speak. Some of these conversations focused on open discussions of local natural hazards and their impacts.

One focus group session was held on November 20th, 2018, to gain additional perspective on natural hazards in the community by creating participatory maps. The group consisted of three male and two female participants ranging in age from 25-51. Members of the community and the Comfort Castle Red Cross Community Disaster Response Team members were present. Participants created three separate maps for the communities of Ginger House, Comfort Castle, and Mill Bank, each displaying residential, business, governmental, and community organization buildings, bridges, roads, natural resources, and hazardous locations. Each feature is color-coded for straightforward interpretation. At times, participants drew the features themselves. Upon their request, the researcher drew as participants dictated. Once complete, participants discussed why they drew certain features, what stands out, what is missing, and what the maps say about their community in terms of strengths and weaknesses. Notes were taken to capture the essence of these discussions and the interactions among the participants throughout the activity. During this session, the participants completed a map for all three communities in ED along the Rio Grande Valley Road.

Difficulty in gathering the same participants to complete the maps of Mill Bank and Ginger House resulted in different groups of participants finishing the remaining maps. Drawing each map took about one hour. Two female community members between the ages of 50 and 55 completed the map of Mill Bank. One male and two female community members between the ages of 50 and 60 completed the map of Ginger House. Again, they drew most of the features, but at times asked the researcher to draw while they instructed.

An IRB amendment was submitted and approved on September 6th, 2018, to conduct semi-formal interviews with open-ended questions relating to natural hazards. Community members participated in a total of 20 interviews ranging from 20-60 minutes. Participants were selected based on existing rapport or referral by another participant. Each participant answered three questions: (1) what is a natural hazard/disaster, (2) what natural hazard/disaster occurs most frequently, and (3) which natural hazard/disaster causes the most damage? Both men and women ranging in age from 24 to 65 participated. Information on local hazards, preparedness, past events, climate change, and government response to disasters was collected. An additional seven interviews were conducted from December 2019 to January 2020 focusing on the relationship between community members and the Rio Grande Valley Road. Lists of interview questions can be found in Appendix A and B. At the beginning of each interview, participants gave oral consent. Responses were recorded by the researcher using detailed notetaking, identities remained anonymous as they were not recorded. Most interviews were with one or two participants and took place in their home or a community space such as the school or resting spots along the road. 
Qualitative data analysis utilized ATLAS.ti, a software used by social scientists to extract underlying and connecting themes. Codes and memos applied to participant observations and focus group notes, along with interview responses, highlight quotes and categorize them into code groups based on themes. Reports generated using ATLAS.ti assist the researcher in identifying underlying themes within the code groups. Those themes are the basis of the in-depth findings from the qualitative data analysis.

\subsection{GIS Analysis}

The geologic data collected complements the ethnographic data and results. Both are incorporated in this thesis to show the salient interaction between humans and their environment that transform natural hazards into disasters. In 2007, the Mines and Geology Division of Jamaica completed a landslide susceptibility zonation project for the parish of Portland (Bhalai, 2010). The project produced Geographic Information Systems (GIS) landslide susceptibility data. Two GIS analyses quantify the potential impact of landslide hazards. Section 3.2.1 details the analysis used to determine the susceptibility of the Rio Grande Valley Road to landslide hazards. Section 3.2.2 demonstrate how the number of people potentially impacted by landslide hazards was determined through GIS analysis.

\subsubsection{Road Susceptibility to Landslide Hazards Analysis}

The GIS analysis in this thesis utilizes the landslide susceptibility data along with data for the Rio Grande Valley Road to reveal where the two layers intersect. As a result, road sections are classified with negligible to low, moderate, moderately high, high, or very high landslide susceptibility.

A Keyhole Markup Language (KML) file of the road was produced with Google Earth. To generate the road, a new line feature was created by placing points on a Google Earth map, generated from satellite images, aerial photographs, and GIS data, along the road from Mill Bank to Port Antonio. Once completed, the file was exported as a KML file and brought into ArcMap using the Conversion toolbox to convert the KML file to a layer.

The landslide susceptibility data received from the Jamaican Mines and Geology Division is projected using the Jamaican Datum 1969 (JAD69), and the road shapefile from Google Earth is projected in World Geodetic Coordinate System 1984 (WGS84). Completing an analysis with landslide and road data layers projected in these different coordinate systems is not feasible, as the JAD69 and WGS84 coordinate systems are not compatible (Newsome \& Bruce, 2003). To perform an intersection with the Rio Grande Valley Road layer, the landslide susceptibility layer was transformed from JAD69 to WGS84. Additionally, adding new layers after this point would be less arduous. Layers will only need a simple WGS84-compatible projection, whereas projecting layers into JAD69 will require two steps, a transformation, and a projection. 
Block shift parameters suggested by Glendon G. Newsome and Bruce R. Harvey from their GPS Coordinate Transformation Parameters for Jamaica paper, were applied to transform and project the landslide susceptibility layer to WGS84. First, a custom geographic transformation required the parameters in table 3.2.1 and the Molodensky geographic transformation method. The Projection and Transformations tool from the Data Management toolbox in ArcMap completed this step. The positive parameters in table 3.2.1 transformed the landslide susceptibility layer from JAD69 to WGS84. Once transformed, the layer is projected into WGS84, also using the Projections and Transformations tool from the Data Management toolbox in ArcMap.

Table 3.2.1. Parameters used to transform layers between WGS84 and JAD69 (Newsome \& Bruce, 2003).

\begin{tabular}{|c|c|}
\hline Parameter & WGS84 to JAD69 \\
\hline Dx $(m)$ & $-65.334 \pm 0.96$ \\
\hline Dy $(m)$ & $-212.460 \pm 1.49$ \\
\hline Dz $(m)$ & $-387.630 \pm 0.69$ \\
\hline
\end{tabular}

Once the Rio Grande Valley Road and landslide susceptibility data were ready for analysis, the Intersect Geoprocessing tool was used. The Intersection Geoprocessing tool "calculates the geometric intersection of any number of feature classes and feature layers," as defined by Esri. ${ }^{17}$ Figure 3.2.1 shows a visual representation of applying the ArcMap Intersection Geoprocessing tool. Both the Rio Grande Valley Road and landslide susceptibility layers were selected as the input features and resulted in an output feature representing where the two layers overlap. This output feature is referred to as "intersect." The intersect is divides the road into segments corresponding with various degrees of landslide susceptibility. Adding a new field called "Length_mi" to the "intersect" attribute table enables "calculate geometry" to determine the length of the road segments.

\footnotetext{
${ }^{17}$ Esri. Source: https://desktop.arcgis.com/en/arcmap/10.3/tools/analysis-toolbox/how-intersect-analysisworks.htm
} 

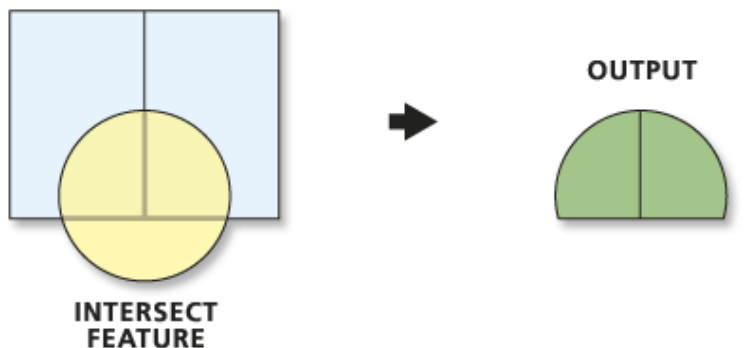

Figure 3.2.1. Intersection Geoprocessing tool result. Input shows the two feature classes (one yellow and one blue). Output shows the overlap of the feature classes. Figure sourced from https://pro.arcgis.com/en/pro-app/tool-reference/analysis/intersect.htm

\subsubsection{Population Impact Analysis}

To further understand the impact of landslide hazards, this second GIS analysis quantifies the number of people that would be affected if a landslide occurs along the road, cutting off the Rio Grande Valley. First, a polygon shapefile of Portland's EDs with population attributes was acquired from the Statistical Institute of Jamaica. Next, two locations along the road are chosen to simulate landslide roadblocks. The first location, Friday, is chosen because of the area's high to very high susceptibility of landslide hazards and history of repeated landslide events. Windsor, the second location, is also chosen due to the location's high susceptibility for landslide hazards. To find out the number of people impacted, the ArcMap Watershed tool was used to determine the affected area.

Since the only way in and out of the valley is to travel north towards Port Antonio, determining the area behind each landslide location yields the impacted area. The Rio Grande Valley Road starts at an elevation of 206 meters and ends at 19 meters in Port Antonio, running parallel to the Rio Grande River. The road's elevation change and proximity to the river provide the ability to determine the affected area from a landslide at the Friday or Windsor location using the Watershed tool. Pour points based on the river's elevation adjacent to the landslide location adjusts the watershed's low point. One watershed for each landslide location is created using the corresponding pour point. Identifying the area hydrologically above the landslide location, or watershed, simulates the affected area from a roadblocking landslide. The watersheds, or affected areas, are converted into polygons to determine the population within those boundaries by using the Geoprocessing Intersection tool. 


\section{Results}

\subsection{Qualitative Results}

Ethnographic data collected from participant observation, focus groups, and semiformal interviews illustrate local perceptions of natural hazards and associated impacts in Comfort Castle. Analysis of the data, coding and memoing, reveals a link between two themes, vulnerability of place and accessibility. Vulnerability of place acknowledges the contribution of social conditions and geophysical risks to a community's vulnerability (Cutter et al., 2000). Accessibility relates to available opportunities and resources that incorporates factors such as physical location, infrastructure, distance to markets, road quality, and entry points to Comfort Castle (Cervero, 1990).

A gravel road littered with potholes, the Rio Grande Valley Road winds through mountainous terrain, encountering switchbacks and hairpin turns. The road condition decreases the environment's safety, therefore, increasing geophysical vulnerability. Social implications also result from the road's poor condition and limited accessibility of Comfort Castle. Limited access to opportunities such as education, economic, health, and other livelihood resources is affected, increasing social vulnerability. Poor road quality would be classified as an "unsafe condition" in the Pressure and Release (PAR) Model, see figure 4.1.1 (Wisner et al., 2004). However, the community's accessibility is a linking theme that can affect and intensify the root causes, dynamic pressures, and unsafe conditions in the PAR Model. Accessibility and the effects of poor road quality, with social and geophysical implications, fit across the entire spectrum of the PAR Model from roots causes to hazards, not just unsafe conditions. In Comfort Castle's case, vulnerability of place is caused by limited accessibility. The PAR Model depicts a magnifying glass referring to the Access Model which identifies how earning a livelihood depends on access to material, social, and political resources, and influences vulnerability (Wisner et al., 2004). While the model acknowledges that accessibility plays a role in vulnerability, it does not consider what factors can restrict or expand physical access. Understanding these factors is crucial to identifying the root causes of vulnerability and mitigating it at the deepest level. 


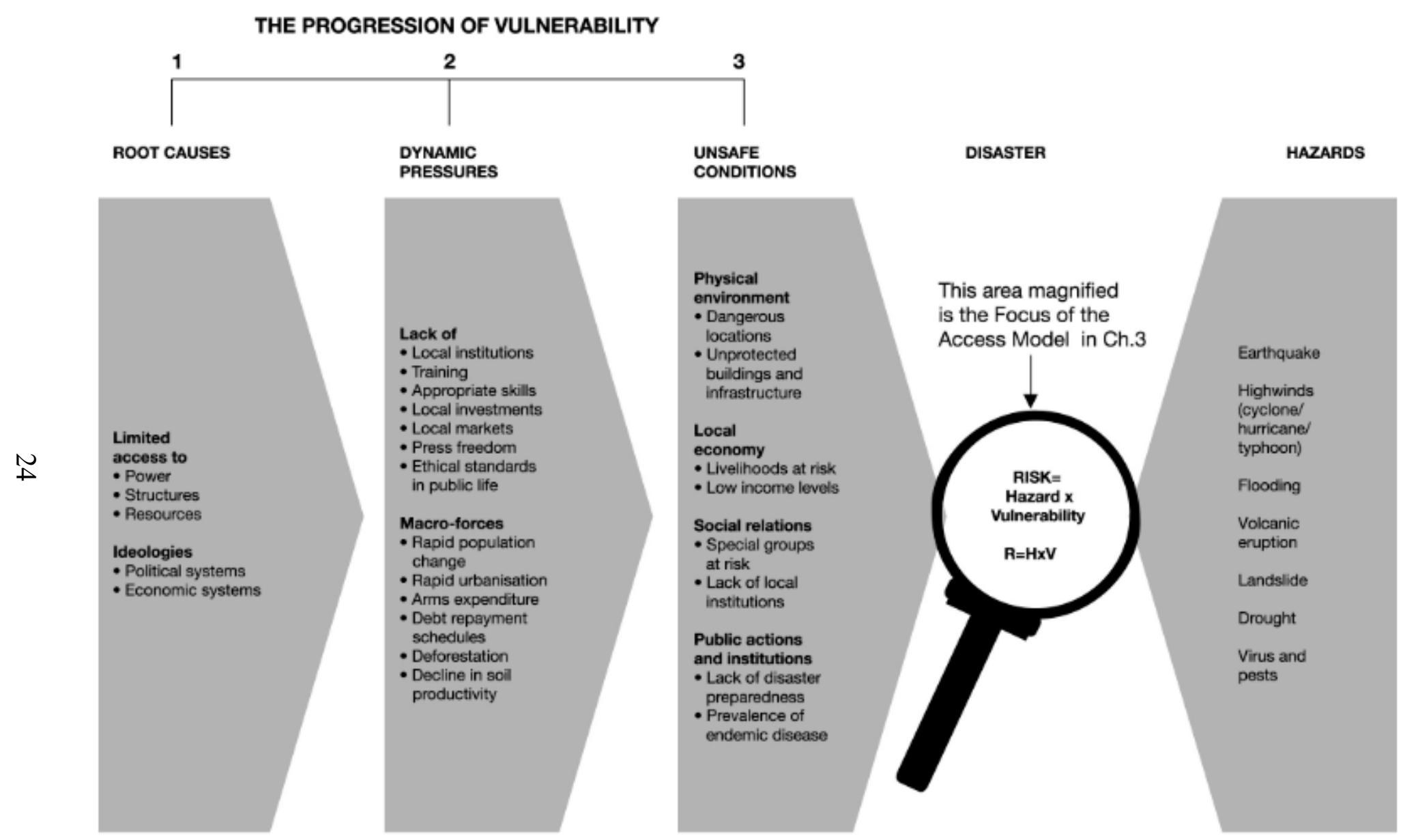

Figure 4.1.1. Pressure and Release (PAR) Model showing the progression of vulnerability and interaction between hazards and vulnerability that produce a disaster (Wisner et al., 2004). Permission to use the figure is located in Appendix C. 
At one time, the Rio Grande Valley Road was in good condition, with a paved surface. Roughly 25 to 30 years ago, the government decided to construct a new road and began by crushing and removing the existing surface. Construction halted after this point leaving behind a dirt and gravel road with small remnants of the cement surface remaining. Some community members say a change in political party representation stopped the project. From this point, the road began to deteriorate as the dirt surface cannot withstand the impacts of the location's heavy annual rainfall. Sections of the road have pools of water most of the year. Residents refer to one location between Ginger House and Comfort Castle as "wet-wet," this portion of the road has water on the surface throughout the year. Over the years, the Rio Grande Valley Road has become increasingly rough and bumpy; potholes are frequent. The road quality is difficult on vehicles, requiring frequent repairs. To avoid damage to their personal vehicles, owners prefer using public transportation.

Many residents talk about poor quality as being the main problem for accessibility and community development. No participants mention the distance to Port Antonio, how far up the valley the community is, or the fact that there is only one road. From the researcher's perspective, countless conversations with residents focus on the road quality since there is potential to improve its quality, it was once in good condition. Community members remember when the Rio Grande Valley Road was paved over 25-30 years ago. To them, if it was paved then, it should be paved now. The second round of semi-formal interviews focusing on the road was conducted to further understand the relationship between the Rio Grande Valley Road and Comfort Castle community members. Refer to Appendix B for a list of the questions asked during these interviews. Participants explain their experience with the road as follows:

"Bad experience. Bad because it is bumpy and takes a longer time to get someplace. Hard in emergency situations, pregnant women end up giving birth in the car. Going down [to Port Antonio] is too slow."

"The road needs to fix; people are afraid of the bad road. The road is the most important thing up here. It's terrible and difficult when you need to go during an emergency. It punishes you; they should have done something by now. A nextgeneration should not come and see this road."

"Over the years, the road has been rough; it needs improvement. If it was better, there would be more people here, and they would do more business. The condition causes people to leave."

"I am 60 years old, and for all the years I have lived in Comfort Castle, the road has never been proper, and it needs to be fixed."

Several responses call for action to repair the road, and others describe the impact of its poor quality. The participants highlight the negative effects of the road's condition and their bad experiences with the Rio Grande Valley Road. 
Based on participant observation and data analysis, the Rio Grande Valley Road is vital to the community as it is the only road in and out. South of Mill Bank, the road turns into a walking path; all vehicles must travel on the northern side to access the community. It is a critical lifeline that impacts various aspects of daily life; residents rely on it to travel out of the valley and to Port Antonio, the nearest market town. The Rio Grande Valley Road provides the only option to access outside resources by vehicle such as economic, health, education, employment, and other livelihood resources that are not available in Comfort Castle

From the initial coding and memoing analysis, eight codes are chosen for analysis. The selected codes in table 4.1.1 are analyzed based on their frequency throughout the qualitative data and their connection to vulnerability of place and relationship with the Rio Grande Valley Road.

Table 4.1.1 Analyzed codes and their number of uses

\begin{tabular}{|l|c|}
\hline \multicolumn{1}{|c|}{ Analyzed codes } & Number of Uses \\
\hline hazard impacts & 71 \\
\hline lack of resources & 43 \\
\hline financial limitations & 29 \\
\hline personal experience & 40 \\
\hline education & 32 \\
\hline preparedness & 31 \\
\hline government response & 61 \\
\hline lack of political power and representation & 39 \\
\hline Total - all codes & 757 \\
\hline Total - analyzed codes & 346 \\
\hline Percentage of codes used for analysis & $45.71 \%$ \\
\hline
\end{tabular}

Sub-sections 4.1.1 through 4.1.5 below, analyze each code to better understand vulnerability of place and accessibility in Comfort Castle. The codes represent root causes, dynamic pressures, and unsafe conditions that create vulnerability from underlying social and geophysical factors in Comfort Castle (Wisner et al., 2004; Cutter et al., 2000). All five of the subsections provide the following information: (1) summary and description of the code, (2) how to code relates to vulnerability of place, and (3) the effects of accessibility on the code's contribution to vulnerability of place.

\subsubsection{Hazard Impacts}

As shown in the PAR Model, hazard impacts inherently combine with vulnerability to generate disasters (Wisner et al., 2004). The degree of vulnerability and type and magnitude of hazard impacts will determine the extent to which disasters affect communities. Hazard impacts affected by social and geophysical factors influence vulnerability of place. 
First, an understanding of the types of natural hazards that Comfort Castle encounters is needed to analyze the relationship of hazard impacts with vulnerability. Interview participants answered the following questions to provide a snapshot of natural hazards in Comfort Castle: (1) what natural hazard produces the most damage, and (2) what natural hazard occurs most frequently. The responses indicate that hurricanes produce the most damage $(68.8 \%)$, and floods occur most frequently $(38.5 \%)$, see figures 4.1.1.1 and 4.1.1.2.

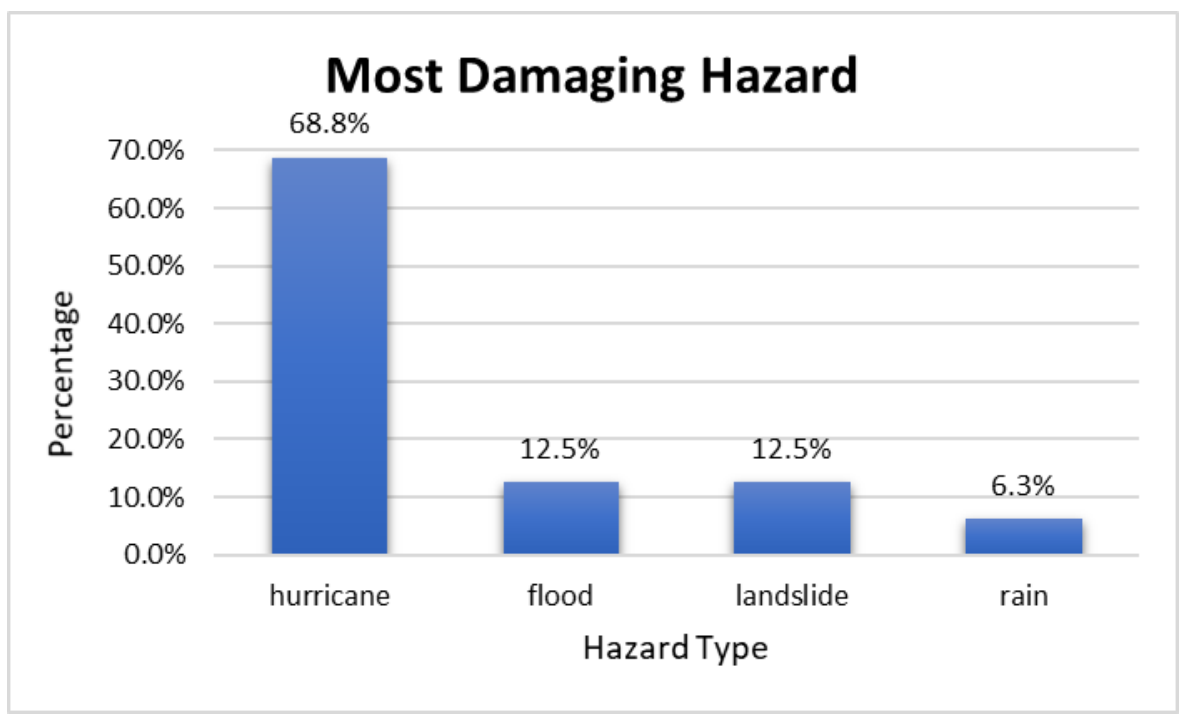

Figure 4.1.1.1 Percentage of responses for the most damaging natural hazard in Comfort Castle gathered from semi-formal interviews.

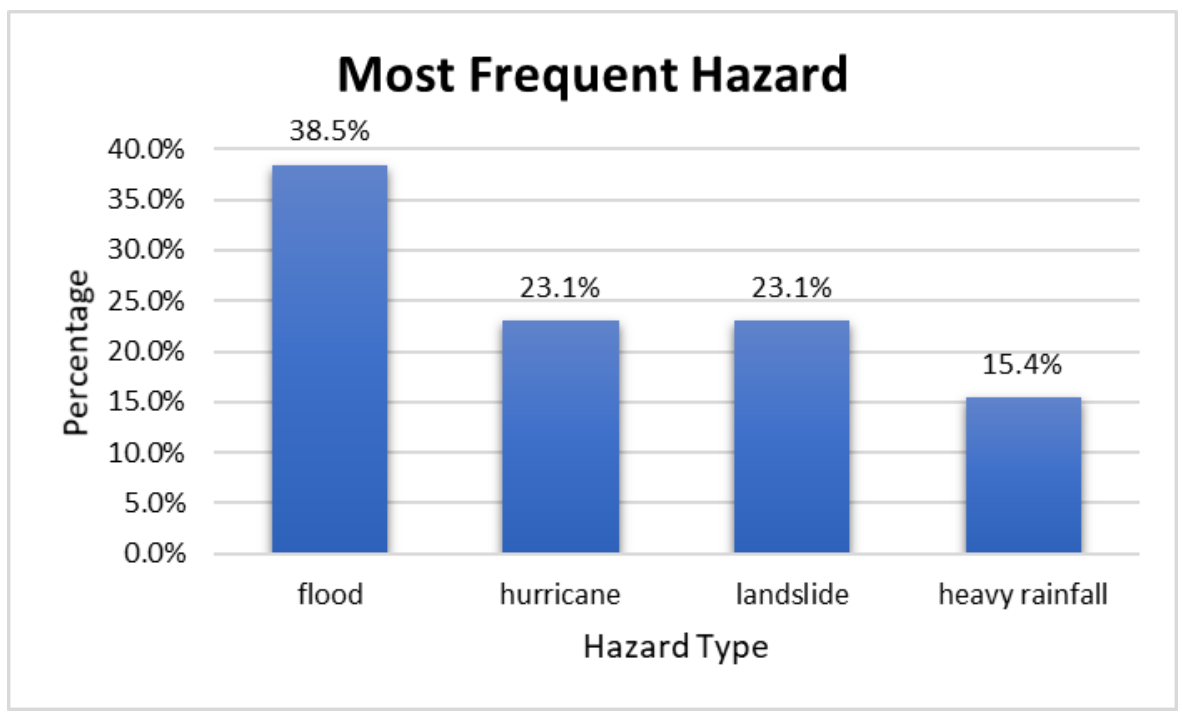

Figure 4.1.1.2. Percentage of responses for the most frequent natural hazard in Comfort Castle gathered from semi-formal interviews. 
In Comfort Castle, hurricanes, floods, landslides, and heavy rainfall directly impact and threaten livelihoods, accessibility, and community development. Several interview participants depict local impacts from natural hazards and how they affect Comfort Castle:

"Hurricanes, they are the biggest threat. They affect houses and fields (farmland)."

"Riverbanks shift, sometimes coming towards and threatening people's property."

"Hurricane Gilbert affected the development of Jamaica in terms of import, export, tourism, and debt."

"Landslides, they affect roads and houses."

Damage to personal property, livelihoods, and community resources from hazards, such as hurricanes, riverbank erosion, and landslides, are devastating and create long-term impacts, requiring additional recovery time. Lingering unmet needs from this recovery process can increase social vulnerability when new disasters occur.

Interview participants recall major riverine flooding in 2016, producing high floodwaters and washing away the Ginger House Swinging Bridge situated on the Rio Grande Valley River. This bridge provides a lifeline as an additional access point for communities on both sides of the river. From 2016 to 2019, residents waded through the river when water levels were low to reach the other side. One participant describes their recollection of the event:

"The last flood was in 2016 and debris from the flood "lick" down the bridge to Cornwall Barracks. ${ }^{18}$ Now there is no bridge, leaving a big effect on communities on both sides of the river."

The local government replaced the bridge three years later in 2019. However, Comfort Castle's geophysical vulnerability increased significantly during this time, as the Rio Grande Valley Road was the only viable access point. The road is also susceptible to roadblocks from landslides and washouts that cutoff the community.

Participants also describe the prominent impact of the 2011 Friday landslide on the Comfort Castle District. ${ }^{19}$ This major landslide completely blocked the Rio Grande Valley Road, disconnecting Ginger House from Comfort Castle and Mill Bank. To travel, residents from Mill Bank and Comfort Castle rode public transportation to one side of the

\footnotetext{
18 "Lik" is Jamaican Patwa word meaning to hit or strike down.

19 Jamaica Gleaner. Source: http://jamaica-gleaner.com/gleaner/20110210/news/news2.html
} 
landslide and walked over the hill, where the landslide originated, to catch transportation in Ginger House on the other side to Port Antonio. A resident describes the impacts of the Friday Landslide:

"Down by Friday, a big landslide cut off the road. Vehicles could not cross. People must walk up over the hilltop and come down. It took a while for them [the government] to start fixing it. Some people crossed the river into Cornwall Barrack to leave the valley and go into Port Antonio."

Debris removal and complete restoration of the road took a long and great effort. At this time, government response to additional disasters in Comfort Castle and Mill Bank would have been delayed and limited to air support, increasing the area's geophysical vulnerability. Access to livelihood resources such as education and employment is also reduced, affecting social vulnerability. Future disasters could generate similar impacts as the Friday landslide and 2016 flood and increases the community's vulnerability of place.

Hazard impacts negatively affect access to employment, educational, and other livelihood resources, increasing social vulnerability. Several farmers in Comfort Castle own land on the east side of the river. When the Ginger House Swinging Bridge washed away in 2016, wading through the Rio Grande River was the only alternative for farmers to reach their land. During periods of heavy rainfall, the river level and speed increase significantly, creating a dangerous environment for those who attempt to cross. Farmers are unable to cross the river and work during these times, affecting their livelihood and reducing their income. Social vulnerability increases for farmers who rely on their work for subsistence and employment. Two residents speak to the impact of hazards on farming:

"Flooding inhibits the farmers from crossing the river to tend their farms."

"Many farmers lose their crops during these disasters and it takes them back to zero which affects them for many years afterward. It is hard on the community because people rely on farming for employment.

Accessibility of Comfort Castle influences the impact of hazards on the community and contributes to geophysical and social vulnerability. Topography, geographic location, and poor road quality seclude Comfort Castle, limiting accessibility during regular times and delaying government response during disasters. Hazard impacts exacerbate limited accessibility and government response time when landslides, fallen rocks or trees, washouts, and high floodwaters block the Rio Grande Valley Road. Several participants share how the road affects the government's response to disasters in Comfort Castle:

"The road condition has a big effect on the community and response from outside help during disasters." 
"The road condition makes it difficult for the government to access the community. The government can use a helicopter if they need to."

"Roadblocks delay how quick government aid can reach Comfort Castle."

Accessibility also incorporates quality and geographic location. Made of loose gravel and located along steep ridges, the Rio Grande Valley road is susceptible to hazard impacts. A lacking drainage system and poor building material make washouts likely to occur. The road cuts through a winding mountainside and along the steep, eroding banks of the Rio Grande River. Many portions of the road intersect landslide-prone areas. Landslides are likely along road sections that cut into the mountain, creating steep slopes. Residents depict the reasons for the road's susceptibility to natural hazards:

"The road is narrow and more likely to be completely blocked by a landslide."

"There is no maintenance on the road many drains are clogged, and they don't properly repair it."

Individually, hazard impacts and accessibility create hardships for Comfort Castle. However, the degree to which hazards impact the community directly correlates with the level of accessibility. Comfort Castle has low accessibility, to begin with, worsening hazard impacts. If alternative roads or bridges existed, the Friday landslide and 2016 flood would not have left such devastating impacts. Farmers could reach their farms when river levels are high to maintain their income and livelihoods. When landslides occur, the communities will maintain access to livelihood resources. The relationship between hazard impacts and accessibility contributes to geophysical and social vulnerability.

Comfort Castle district comprises three communities, Comfort Castle, Ginger House, and Mill Bank. Focus group participants created three participatory maps, one for each community. Hazardous areas delineated are based on the location of past events and places where hazards could occur. For example, the participants consider two bridges along the road hazardous because they are in poor condition. Participants referred to personal experiences to identify these hazardous areas within the communities. All hazardous areas are along the road, and participants identified flooding, landslides, and bridge failures as hazards. When asked if the hazardous areas have changed over time, participants said flooding areas had remained the same while landslide areas are increasing in size and occurring in new locations. The final participatory maps are shown below in figures 4.1.1.3, 4.1.1.4, and 4.1.1.5 and display relative location and perception of natural hazards in the community. The maps are not true to scale or used for orientation purposes. 


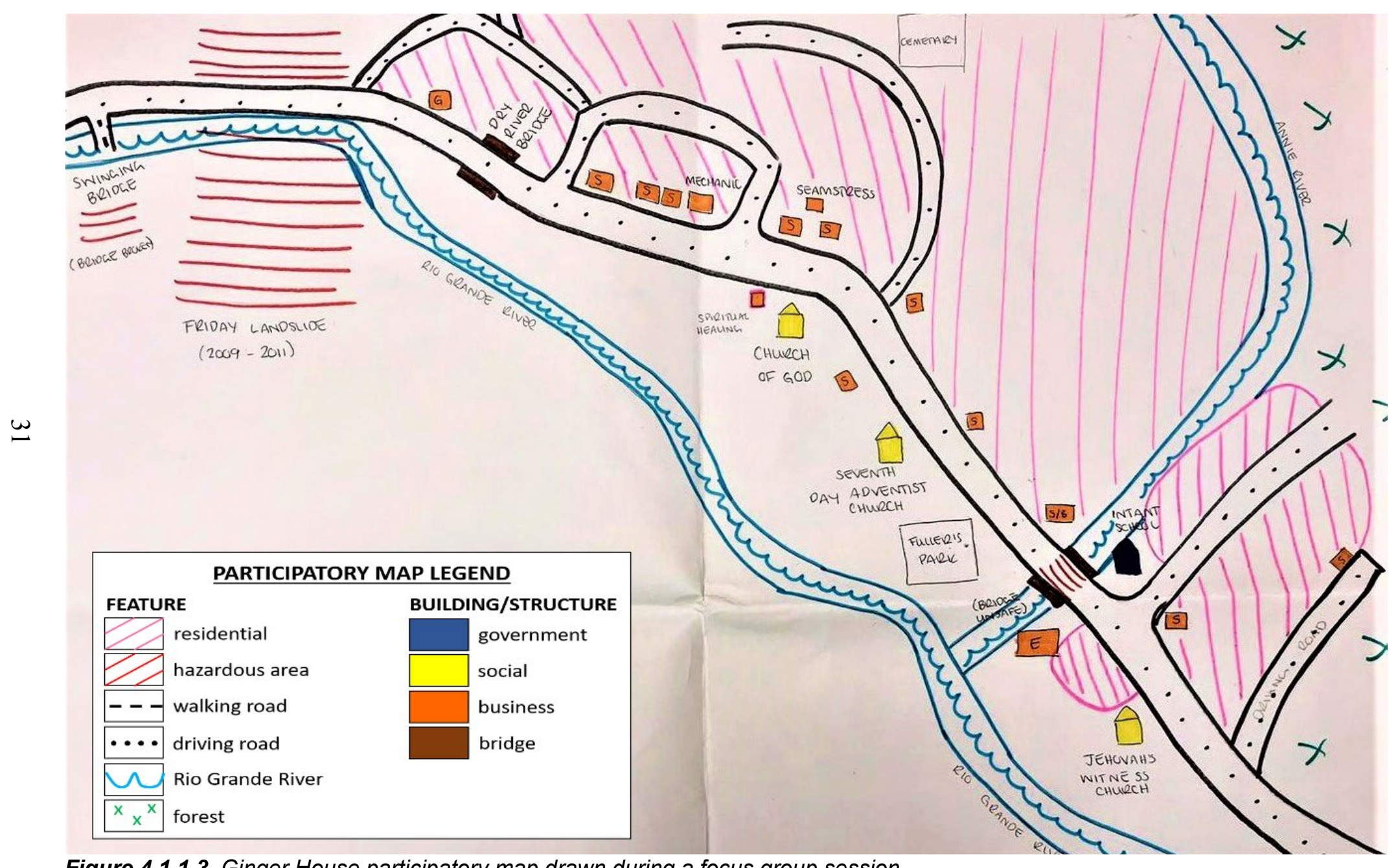

Figure 4.1.1.3. Ginger House participatory map drawn during a focus group session. 


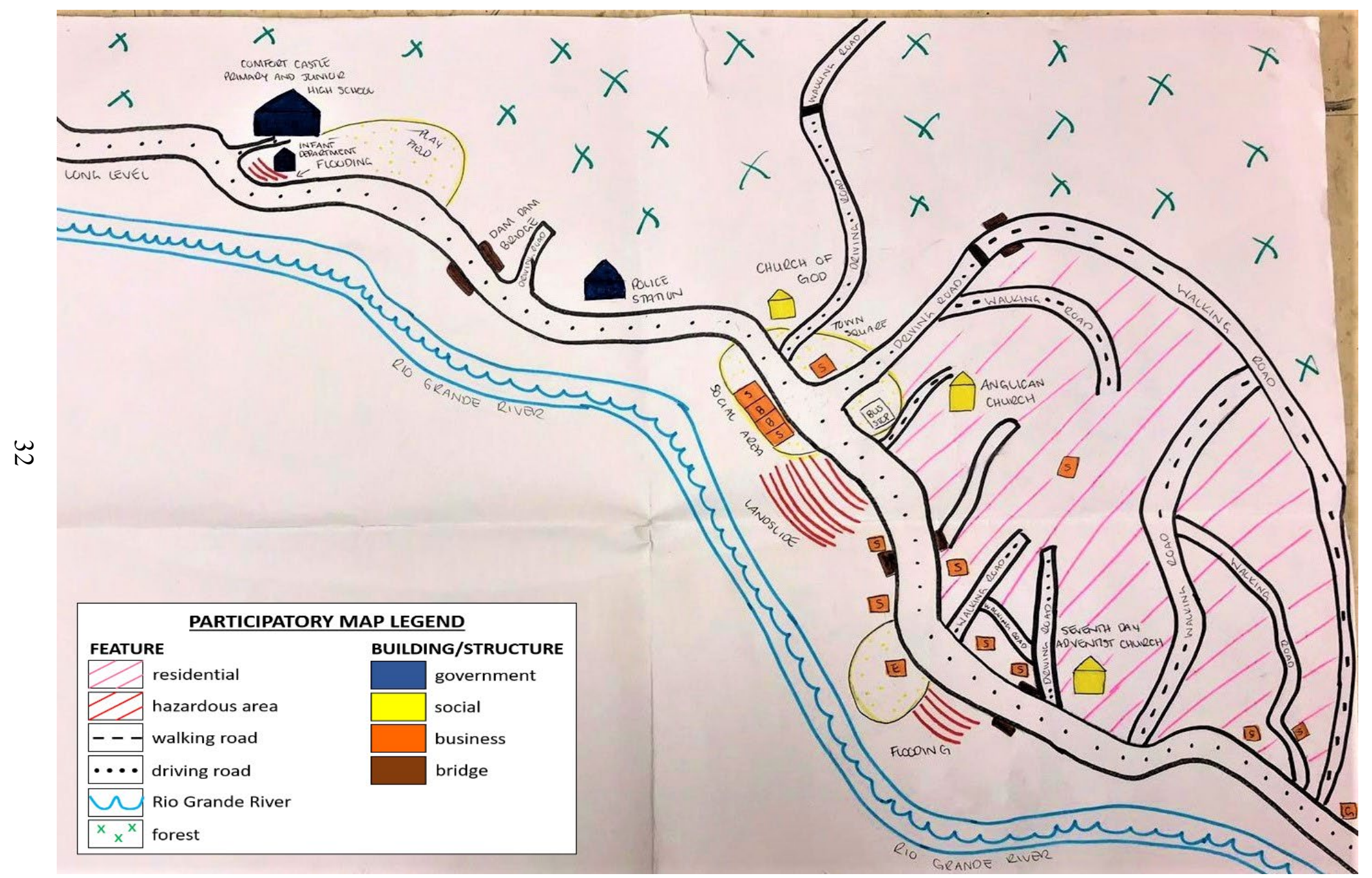

Figure 4.1.1.4. Comfort Castle participatory map drawn during a focus group session. 


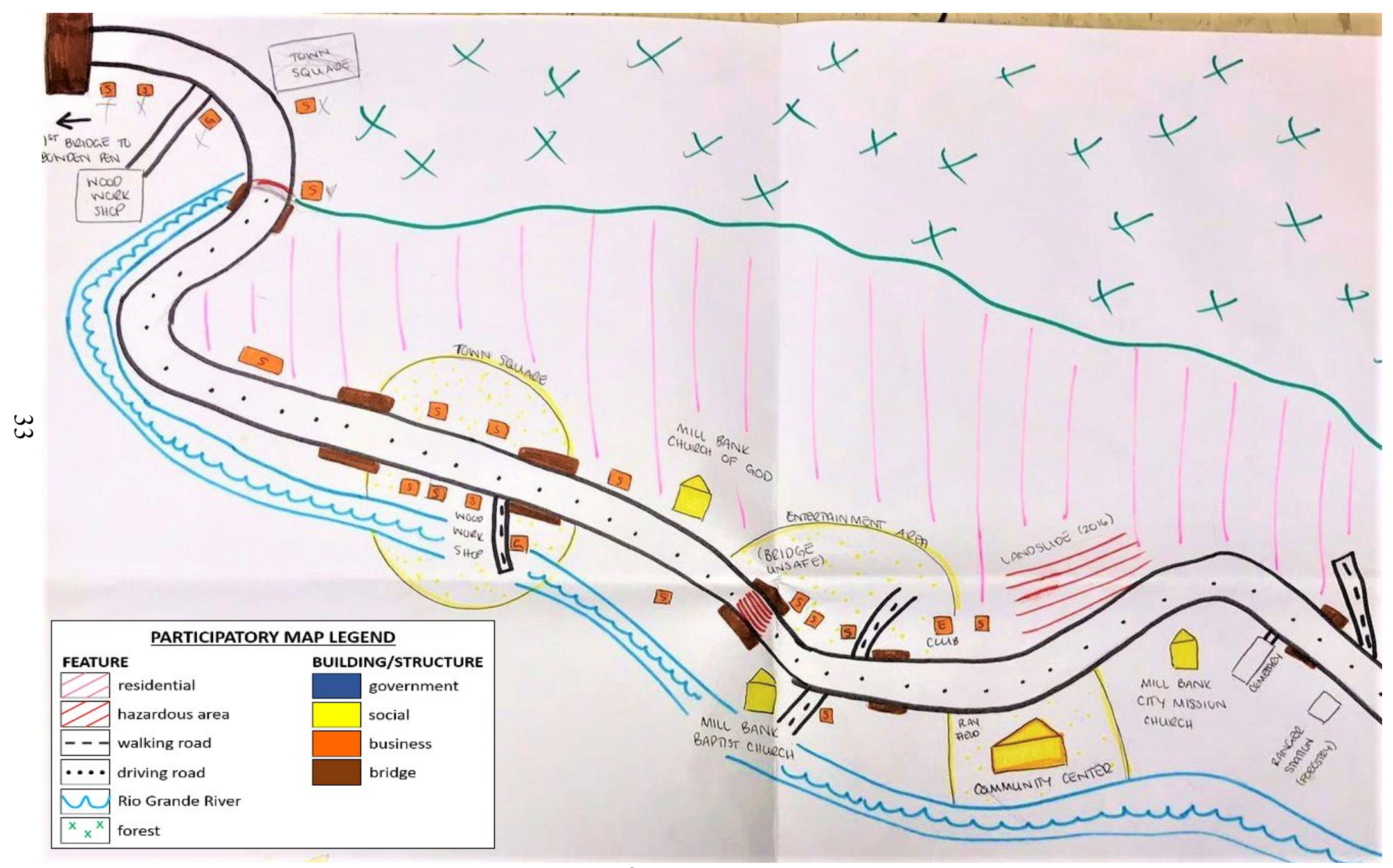

Figure 4.1.1.5. Mill Bank participatory map drawn during a focus group session. 
Hazardous areas on the Ginger House participatory map include Friday, the swinging bridge, and the Annie River bridge near the Basic school. Friday has an unstable slope along the road that has produced several landslides. The broken swingingbridge, which leads to the communities Cornwall Barracks and Moore Town across the river, is also depicted. The bridge is a vital resource for employment, social, and educational purposes. Transportation to Comfort Castle and Mill Bank relies on crossing the Annie River Bridge safely. Currently, the bridge is in poor condition and is marked hazardous as a result.

On the participatory map of Comfort Castle, two locations are in low-lying areas and frequented by flooding events. One is by the Comfort Castle School Infant Department and the other near the Seventh Day Adventist Church. Another location, in the town square, has experienced multiple landslides and is considered hazardous. This area sits along the riverbank and experiences erosion. The slope has become unstable, and landslides are likely during periods of heavy rainfall.

Two locations on the Mill Bank participatory map are considered hazardous. In 2016, a landslide occurred across the road from the community center and the Mill Bank City Mission Church. A bridge near the Mill Bank Baptist Church is unsafe and delineated as hazardous. To date, there have been no incidences with this bridge. However, a possibility exists due to its poor condition. However, a possibility exists due to its poor condition.

\subsubsection{Lack of Resources}

Availability of livelihood resources is limited in Comfort Castle. Residents travel to Port Antonio to pay bills and purchase food, farming supplies, household goods, and construction materials. Port Antonio, the capital of Portland, is the nearest town with extensive employment, health, financial, and continuing education resources. Unfortunately, accessing these resources is challenging for community members. Traveling to Port Antonio is time-consuming and costly, requiring a 60-minute trip and $\$ 250$ JMD (\$1.78 USD). ${ }^{20}$ A lack of local resources and access to outside resources restricts individual and community development. A lack of development decreases the capacity to prepare for, respond to, recover from, and mitigate disasters. One participant expresses the costliness of accessing livelihood resources:

"We have to buy farming supplies in Port Antonio, which is miles away, it costs us."

Physical barriers, including accessibility, influence resource availability to Comfort Castle. The secluded location and treacherous road quality discourage resource

\footnotetext{
${ }^{20}$ Based on current JMD to USD exchange rate from "https://www.exchange-rates.org/Rate/USD/JMD
} 
flow with outside markets or communities. Getting commodities such as agricultural products, bamboo, and lumber to market comes at a cost. Most farmers rely upon public transportation to sell their products at the Port Antonio market. Frequent trips can become costly. Another yet costly option is for farmers to sell their goods to the market truck who sells them to higglas in Port Antonio in return. ${ }^{21}$ However, products are bought from the farmers at a lower rate and the truck only comes to the community once per week due to the long distance. One farmer shares his view about a better road:

"I would be able to sell more corps into the market."

The long and miserable road to Comfort Castle impedes developmental resources from reaching the community. Many residents desire to build cement blockhouses to reduce damages from hurricanes, but increased delivery costs hinder this development. Most of the houses in Comfort Castle do not sit along the road. Many must walk a distance from their house to the Rio Grande Valley Road. One person describes the costly experience of getting supplies up from Port Antonio to their home:

"The cost to take building materials from Port Antonio is costly because it's dropped by the road and then homeowners have to hire men to bring the materials to the house."

Additionally, community development nonprofits and government agencies seldom reach Comfort Castle. During a conversation, the Comfort Castle Primary School principal expressed his frustration about HEART not reaching the community: ${ }^{22}$

"They will not come to the community to assist in educational classes for adults because of the road. They said the road is too bad."

A lack of resources stems from limited accessibility to Comfort Castle, restricting local development and economic growth. Such constraints further increase the community's social vulnerability to disasters.

\subsubsection{Financial Limitations}

Comfort Castle is considered a low-income community partially due to inadequate employment opportunities. In Comfort Castle, jobs are limited in number and generate little income. Employment is available in Port Antonio, but the time and financial commitment for frequent travel outweigh employment benefits for many. The following excerpts express participant needs to focus their income on daily priorities, not disaster preparedness or response measures:

\footnotetext{
${ }^{21}$ Higglas is a Jamaican Patwa word meaning a street vendor, a person who hustles to sells their products. ${ }^{22}$ The Human Employment and Resource Training Trust/National Training Agency, also known as HEART, provides technical vocational education and training. Typically for adults seeking to further their education or pursue trade skill work. Source: https://www.heart-nta.org/
} 
"I would like to have more resources in place but can't always afford to prepare."

"Some people don't prepare because if they spend money to do so and then nothing happens, they wasted money."

"I don't always want to invest in buying supplies so I can save money."

Referring to household repairs... "It didn't take long to fix, but it was expensive to fix. We had to repair what was most important. Had to prioritize what to fix, the most important things had to be fixed first, like the roof."

Financial limitation reduces individual and household capacity to manage disaster impacts. Social vulnerability increases, as a result, creating exacerbating disaster impacts.

Few local employment options exist to boost financial stability. Seclusion of the community and poor road quality make it difficult for development to occur. Bringing job opportunities to the area and for individuals to seek employment outside of Comfort Castle is challenged by limited accessibility. Community members share the benefits of an improved road on employment:

"We would have more businesses and people up here if the road was better."

"I would get more business at my shop along the road."

Accessibility negatively correlates with financial limitations. Better road infrastructure would improve accessibility, therefore increasing individual financial stability and decreasing social vulnerability.

\subsubsection{Personal Experience, Education, and Preparedness}

Education, preparedness, and personal experience are combined in this sub-theme to highlight their complex and dependent relationship related to disaster preparedness. As indicated by the semi-formal interviews, personal experience, education, and preparedness can have a positive and negative correlation with vulnerability. Social vulnerability is interactive; different elements can increase or decrease its effects (Cutter, et al., 2003).

Personal experience is salient to education, especially for natural hazards and disasters. Although individuals learn about disasters through school, news, or their local government, a full understanding comes when coupled with personal experience, which leads to a sense of preparedness. When asked how they learn about disasters, personal experience was the most common answer and often expressed first among other 
educational mediums. Residents reveal how they learn about disasters through personal experience:

"We have been educated about disasters from experiences and stories from others. People are better educated now from experience."

"I have experienced disasters since about 10 and learned about disasters this way."

"I learned about disasters through past experiences. I have been through many disasters and the experience helps to better prepare for future disasters."

Personal experience is educational and can provide individuals with a deeper understanding of their impacts. For one participant, his experience with Hurricane Gilbert provided him better respect for storms:

"Was glad to see it to gain experience. My parents went to the shelter, but I stayed home. I went outside during the storm and gained a better understanding and respect of the storm's strength. I was not afraid.'

As is evident from interview responses, personal experience educates and creates a feeling of preparedness for community members to natural hazards, reducing their vulnerability. Participants also commented on Comfort Castle's ingenuity and can-do attitude. When landslide debris blocks the road, it often takes too long for the government to come and remove the debris. This experience encourages community members to take it upon themselves to remove the debris if the load is manageable, knowing their efforts will clear the road for vehicular traffic and access more quickly.

Vulnerability increases from poorly disseminated information and a false sense of security from a lack of preparedness and personal experiences. At times, disaster-related information is not readily available to the public or understood by vulnerable populations. Several interview participants share their experience with poorly disseminated information:

"We need more awareness of emergency phone numbers to call during disaster events; accessing this information is a challenge."

"People are unaware of hazardous areas and sometimes build in those areas."

After an individual survives a disaster, they might feel they can also survive future events. This false sense of security can leave individuals and the community vulnerable. For example, if an individual survives a category four hurricane, they may feel that they can survive other storms of the same or lesser magnitude. With this mindset, it is forgotten that magnitude or scale is not always indicative of the potential damage. In result, some remain in vulnerable locations and do not heed warnings. Residents explain why some community members in Comfort Castle neglect warnings: 
"We have prepared for hurricanes that never came in the past. This causes people to sometimes neglect hurricane warnings."

"I stayed home [during Hurricane Sandy], I didn't expect such a big storm, next time I will go to a shelter."

Accessibility augments increased vulnerability from personal experience, education, and preparedness. Government and non-government agencies in Jamaica, such as ODPEM and Red Cross, interact with communities to provide educational and informative resources regarding disasters. Poor road quality and remoteness of the community often discourage such agencies from traveling to Comfort Castle. As a result, the community misses out on benefiting from these resources to reduce their vulnerability.

\subsubsection{Lack of Political Representation and Government Response}

A trusting relationship between the government and local communities is essential for hazard mitigation and overall community development; without it, needs are not addressed, capacity building is restricted, and vulnerability increases. The Jamaican government's response to disasters has influenced their negative relationship with the residents of Comfort Castle. While the government does provide aid in the wake of a disaster, a significant disconnect with the community remains. Participants describe the government's inadequate response to disasters in Comfort Castle:

"The government typically only comes once immediately after a hazard."

"More can be done by the government. They should reach out to active community members who know what is going on in the community. By doing so, they'd have a better understanding of the community."

"Comfort Castle is neglected."

"The government should put out more effort."

Participants reveal this disconnect results from political bias when the political party in power does not align with the community's affiliation. Community members feel that they receive less aid and assistance as a result. A lack of communication between Comfort Castle and the government also exists and causes frustration. Residents feel their voices are overlooked and unheard during regular and disaster times. When the community expresses their needs to their government representative, seldom are they addressed. For example, residents will often vote for a Parish Councilor (PC), who represents the Comfort Castle District and promises to fix the Rio Grande Valley Road. It is the responsibility of the PC to lobby for a new or improved road to the Member of 
Parliament (MP) for their region. From there, the MP brings the concern to officials at the national level. Despite the efforts of community members to improve their road through political votes to relay their desire for a new road, little to no effort has been put forth by PCs to lobby for improvements to the Rio Grande Valley Road. One community member illustrates her frustration over the lack of communication and acknowledgment of Comfort Castle's voice:

"They should get feedback from people who are affected. They make rules and expectations without input from community members. The top-down approach causes challenges. More community outreach is needed from the government."

Residents feel that the government is guilty of not upholding promises made during normal and disaster times. Some community members use the Jamaican proverb "Oily tung nuh mus tell di truth" when referring to government promises. The proverb translates to "an oily tongue does not have to tell the truth," meaning be wary of smooth talkers. The negative relationship between Comfort Castle and the government discourages community buy-in to disaster risk management measures proposed by the Jamaican government. Community members do not trust or listen to the government due to political underrepresentation and political bias in the government response to disasters. A lack of political power and representation is a fundamental cause of vulnerability to disasters (Blaikie et al., 2005).

Limited accessibility has a significant impact on the political power and representation of Comfort Castle and the government's response to local disasters. A collective mindset that Comfort Castle is "in the bush" meaning far in the country and hard to reach discourages visits. The poor road quality creates an additional challenge for frequent visits by government officials as the trip is long and consumes most of the working day. Participant responses indicating the negative effect of accessibility on government response to disasters:

"The government doesn't reach secluded/hard-to-reach communities."

"The road condition has a big effect on the community and response from outside help during disasters."

Interview respondents view the road as a political issue. Before or following general elections, minor road repairs are completed, but the road is never fully restored. Nominees make campaign promises to fix the road once they are elected to win votes. Politicians have made such promises for years, yet they are never fulfilled. Many residents have stopped voting in frustration with this political ploy. Trust in the government is further reduced by these actions, increasing social vulnerability to disasters. Locals explain how the promise of road construction is used as a political tactic to win votes: 
"They [the government] come and repair the road every election to get votes, not because they care. They fix the road part way and say they will fix the rest if they are elected."

"Politicians use the possibility of fixing the road as a way to get people to vote for them. Voting is our right, but what are we getting?"

"After or close to a general election, they [the government] will scrape the surface [of the road] to try and make it level, but nothing is added to make it better."

The government's response to disasters and political representation of Comfort Castle has left a substantial and lasting impact on the community. Many residents have lost the government's trust, which will be difficult to regain. It affects the community's capacity to mitigate, respond to, and prepare for disasters, increasing their vulnerability of place.

\section{Ethnographic Analysis Outcome}

Analysis of the ethnographic data indicates how limited accessibility exacerbates the effects of hazard impacts, a lack of resources, financial limitations, personal experience, education, preparedness, government response, and lack of political power and representation and their contribution to increasing Comfort Castle's vulnerability of place. Comfort Castle's vulnerability of place is increased by accessibility's role in the local social fabric and geophysical characteristics.

In the following subsection, local landslide hazards and their relationship with the Rio Grande Valley Road are analyzed using GIS to showcase the geophysical vulnerability of Comfort Castle. As derived from literature and the ethnographic analysis, landslide hazards frequently impact the road, generating transportation interruptions to daily life, increasing both geophysical and social vulnerability. Most community members state that landslide hazards affect the road the most in comparison to other local hazards. When landslides block the road or restrict vehicular traffic, accessibility is further reduced, and vulnerability of place increases.

\subsection{Quantitative Results}

\subsubsection{Road Susceptibility to Landslide Hazards}

Assessment of the Rio Grande Valley Road susceptibility to landslides utilizes the landslide data produced by the Jamaica Mines and Geology Division (Bhalai, 2000). As a result, the road is divided into segments according to landslide susceptibility. The extent of the analysis consists of the entire road from Mill Bank through Comfort Castle and Ginger House to Port Antonio, as shown in figure 4.2.1. Since the Rio Grande Valley is the only road, this analysis incorporates the whole road. A landslide at any point in the 
road would eliminate accessibility between Port Antonio and the Comfort Castle Enumeration District.

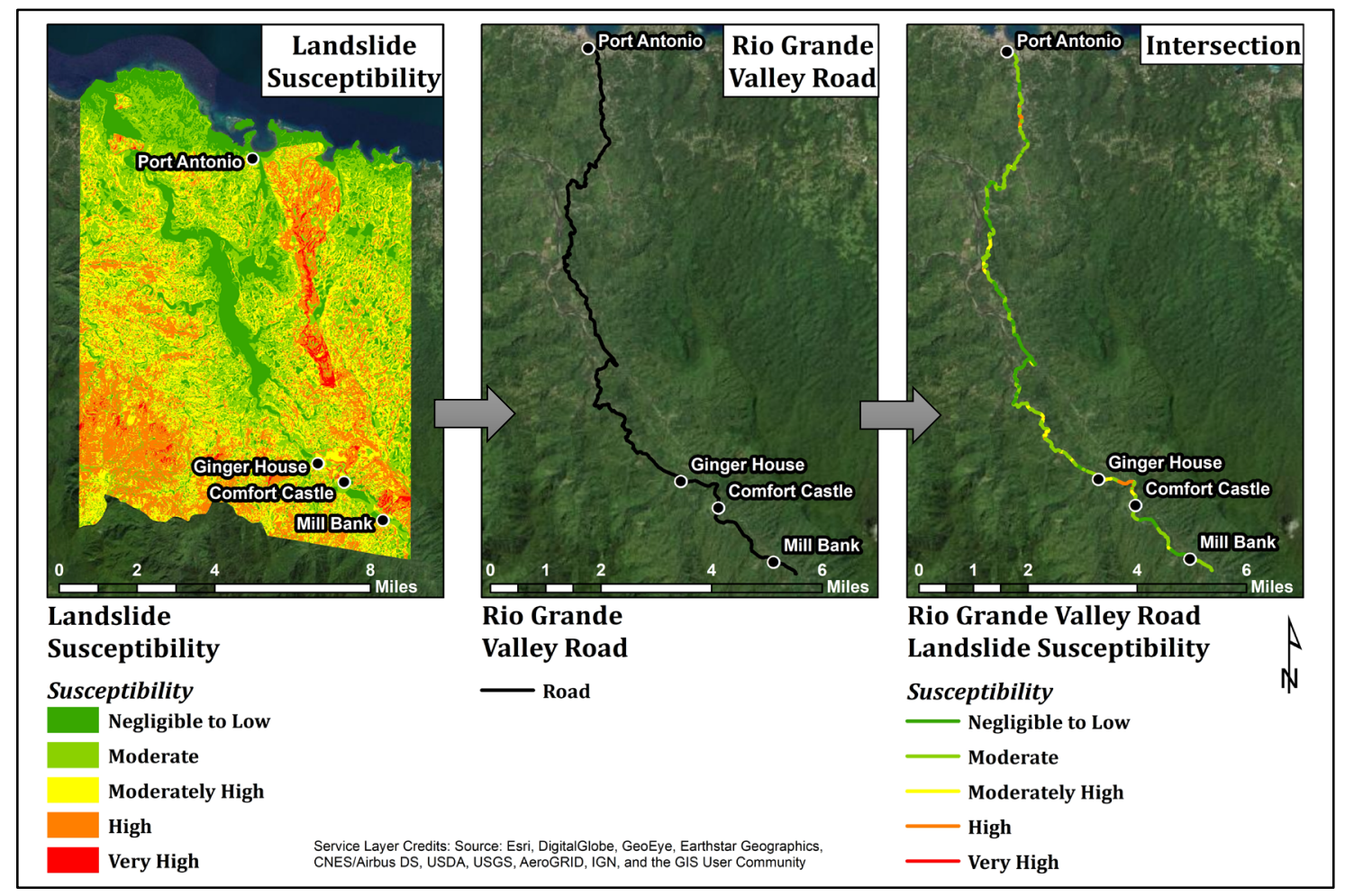

In total, the Rio Grande Valley Road from Mill Bank to Port Antonio is 15 miles

Figure 4.2.1.1. Results of intersection to determine landslide hazard susceptibility of the Rio Grande Valley Road. The Intersection map is the product of overlapping features from the landslide susceptibility and Rio Grande

long. The ESRI ArcMap intersection geoprocessing tool combines the landslide susceptibility and road layers into one layer. Because the landslide susceptibility layer is divided into five classes, when it intersects with the road layer, the resulting intersection layer shows the road divided into segments where the two layers overlap. Each segment correlates to one of the five susceptibility zones and varies in length. In total, the road is broken down into 163 segments. The susceptibility zones include: (1) negligible to low, (2) moderate, (3) moderately high, (4) high, (5) very high. This correlation results from an overlap between the landslide susceptibility data and road data, shown in figure 4.2.1.1.

All seven road segments with very high landslide susceptibility are at Friday, between Comfort Castle and Ginger House, but only make up $0.53 \%$ of the road, see table 4.2.1.1. Notably, $50.13 \%$ of the road segments are moderately susceptible to landslides and constitute 7.54 miles of the road. Moderately high $(14.36 \%)$, high $(6.12 \%)$, and very high $(0.53 \%)$ landslide susceptibility segments consist of the remaining portion of the road. Segments classified as moderate to very high, comprise $71.14 \%$ of the whole Rio Grande Valley Road, as shown in figure 4.2.1.2. 
Table 4.2.1.1. Rio Grande Valley Road segment details for the five levels of landslide susceptibility

\begin{tabular}{|l|c|c|c|}
\hline \multicolumn{1}{|c|}{ Susceptibility } & $\begin{array}{c}\text { Length } \\
\text { (mi) }\end{array}$ & $\begin{array}{c}\text { Percentage of total } \\
\text { length }\end{array}$ & $\begin{array}{c}\text { \# of Road } \\
\text { Segments }\end{array}$ \\
\hline Negligible to Low & 4.35 & $28.92 \%$ & 34 \\
\hline Moderate & 7.54 & $50.13 \%$ & 38 \\
\hline Moderately High & 2.16 & $14.36 \%$ & 61 \\
\hline High & 0.92 & $6.12 \%$ & 23 \\
\hline Very High & 0.08 & $0.53 \%$ & 7 \\
\hline TOTAL & $\mathbf{1 5 . 0 5}$ & & $\mathbf{1 6 3}$ \\
\hline
\end{tabular}

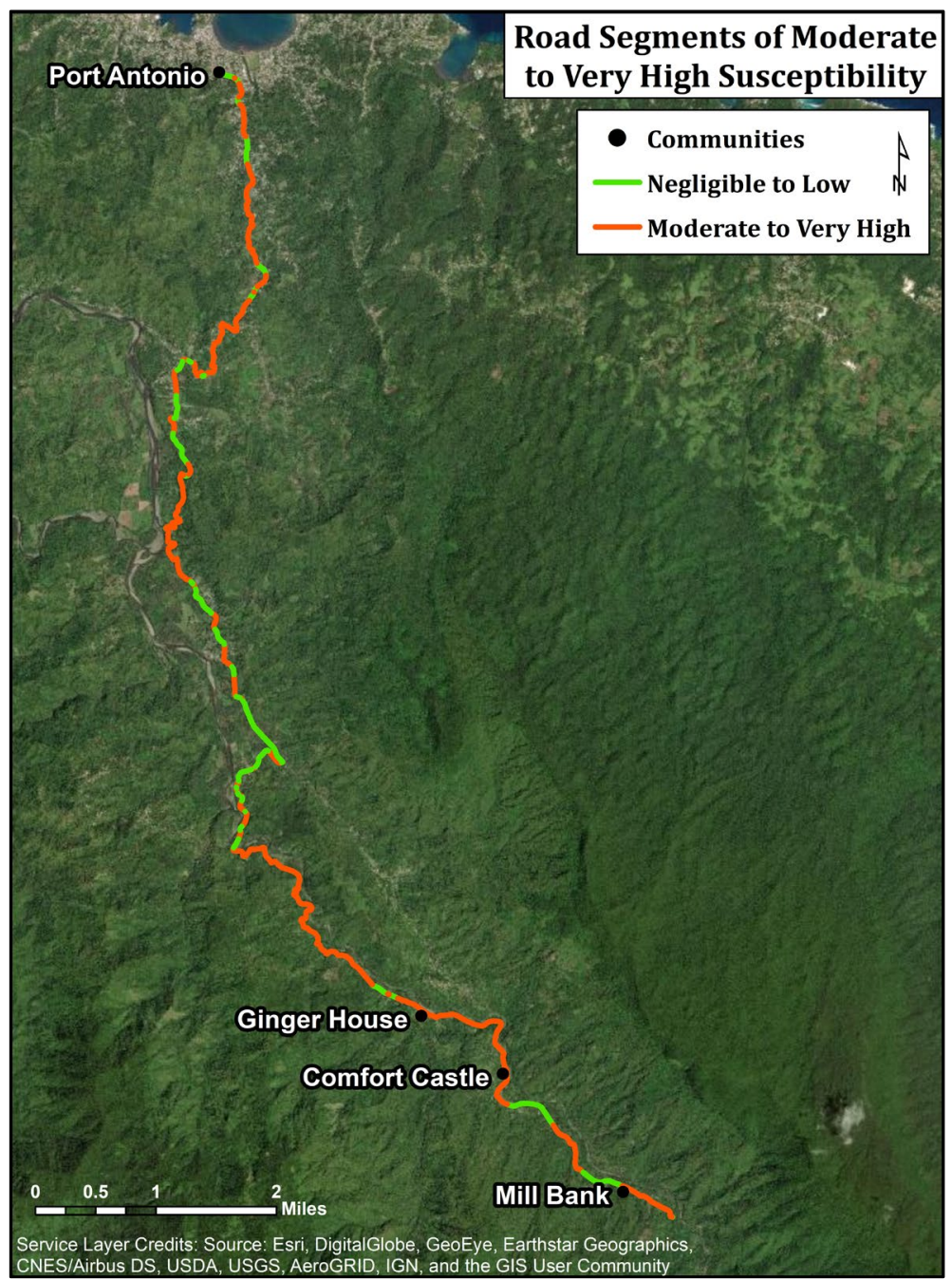

Figure 4.2.1.2. A majority of the Rio Grande Valley Road at risk to landslide hazards. $71.4 \%$ of the road segments intersect with moderate, moderately high, high, and very high landslide susceptibility zones based on the landslide susceptibility mode of Bhalai (2000). 


\subsubsection{Population Impact}

The Rio Grande Valley Road provides the only vehicular access point to the community. Because of its setting within the Rio Grande Valley, landslides do not have to occur within Comfort Castle for residents to feel the effects. If any point along the road north of the community is blocked, Comfort Castle is cut off until the debris is cleared. The landslide susceptibility of the road threatens accessibility for Comfort Castle, as well as all communities within the Rio Grande Valley.

Since all communities from Mill Bank to Port Antonio rely on the road for access, landslides that block the road typically affect more than one, if not many, communities simultaneously. Alternative driving routes are not available. Population data and watershed modeling were used to determine the number of people that would be impacted at two locations along the Rio Grande Valley Road.

Figure 4.2.2.1 shows the cascading effects of landslides that block the Rio Grande Valley Road. A landslide that blocks the road at the Friday location would isolate 1,632. Landslides that occur closer to Port Antonio affecter a greater number of people in the Rio Grande Valley. At the Windsor location, 6,287 people would be cut off from a landslide along the road, affecting an additional 4,665 people. Both locations are chosen based on their high to very high landslide susceptibility. Additionally, multiple landslides have occurred at the Friday location. Landslides along the road have a valley-wide impact.

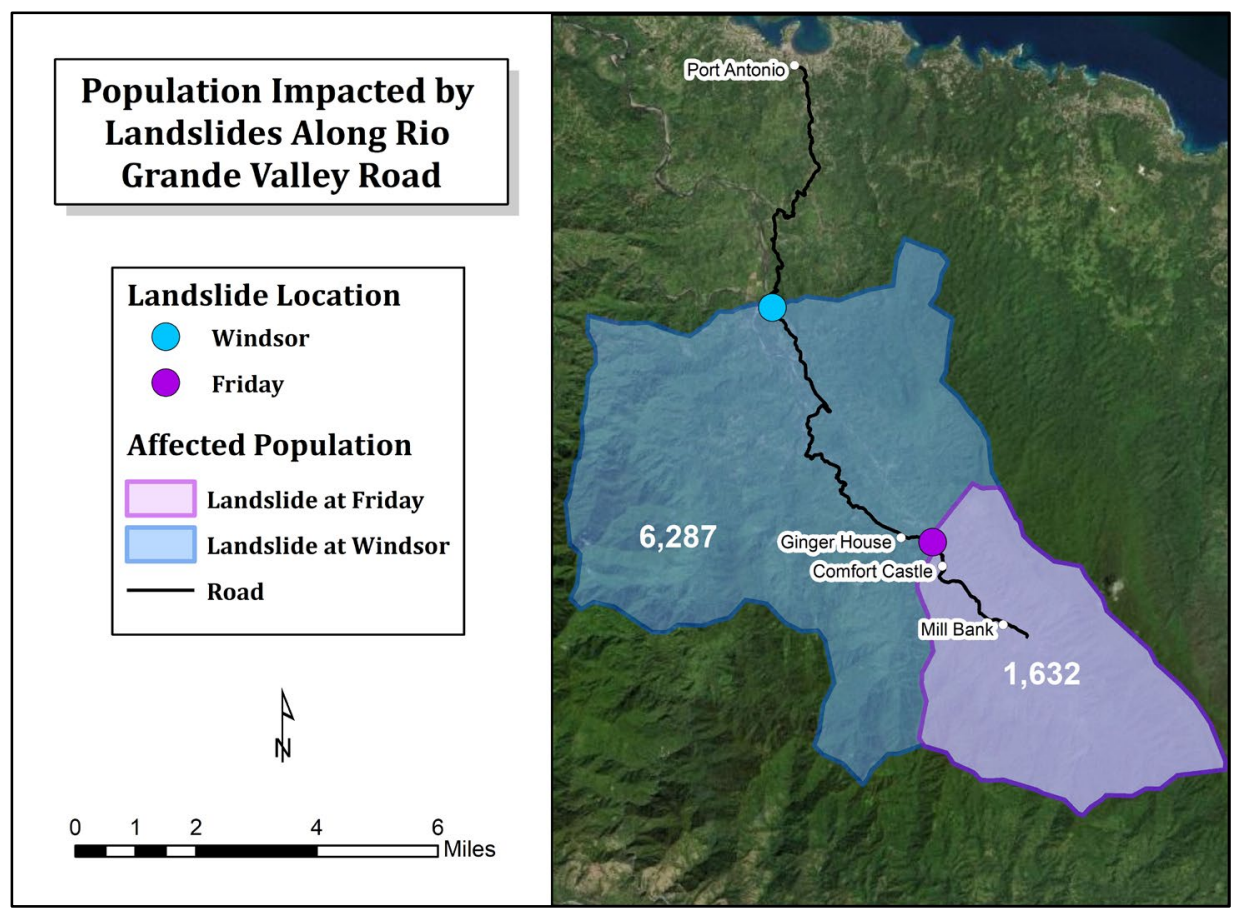

Figure 4.2.2.1. The potential number of people impacted if a landslide blocked the Rio Grande Valley Road near the communities of Windsor or Friday. Both locations along the road intersect with high or very high landslide susceptibility. 


\section{Discussion}

\section{Influence of Road Quality on Accessibility and Vulnerability}

Limited access contributes to vulnerability of place on its own, but also impacts other geophysical and social vulnerability factors affecting Comfort Castle. While availability of opportunities, physical location, distance to market, road quality, and entry points to Comfort Castle are all elements of accessibility, addressing road quality would have the most significant impact. Road quality is also the only element that can realistically change. Altering the physical location and distance is not possible. However, improving road quality would decrease travel time between Port Antonio and Comfort Castle, possibly reversing the mindset that Comfort Castle is far away and hard to reach. Creating additional access points and building new roads would require significant resources due to the mountainous terrain that is not currently available for the existing road. Improving the availability of opportunities outside of Comfort Castle is directly tied to and dependent upon road quality. Improving road quality would diminish the effects of all contributing factors and increase access to Comfort Castle.

Increasing accessibility by improving road quality would decrease social vulnerabilities facing Comfort Castle. The road influences hazard impacts, lack of resources, financial limitations, personal experience, education, preparedness, government response, and lack of political power and representation, as shown by the ethnographic analysis. They are the contributing root causes, dynamic pressures, and unsafe conditions affecting the community's vulnerability, exacerbated by the poor condition of the Rio Grande Valley Road. A new or improved road could provide the following benefits:

1) A decrease in the severity of hazard impacts on people, property, and infrastructure.

2) Provide easier access to additional resources outside of Comfort Castle.

3) Improve financial security through additional employment opportunities.

4) Help residents prepare for disasters through increased education.

5) Provide the ability to implement lessons learned from personal experiences through increased access to resources, services, and opportunities.

6) Shorten government response time to local disasters.

7) Improve the relationship between Comfort Castle residents and local, regional, and national government leadership.

8) Better access to markets and income outside of the immediate area. 
In the Pressure and Release (PAR) Model by Ben Wisner et al. (2004), physical accessibility only fits within the category of unsafe conditions. However, in Comfort Castle's case, it is a common denominator across the entire spectrum, from root causes to hazards. Physical access to the community affects each category that contributes to the causation of disasters since it is the source that generates root causes which lead to vulnerability. Identifying access as a source in vulnerability models takes it a step further by revealing what needs to be mitigated first to start reducing overall vulnerability.

Based on literature and data analysis, landslide hazards frequently impact the Rio Grande Valley Road, often obstructing traffic and limiting access to Comfort Castle. Obstructions at any point along the road from Comfort Castle to Port Antonio prevent travel. The community depends on 15 miles of clear road to access Port Antonio and the rest of Jamaica. Since there is a long distance to Port Antonio, the likelihood of roadblocking landslides affecting travel to and from Comfort Castle is higher. In comparison, access between communities five miles away from Port Antonio is less likely to be impacted by a landslide since their travel distance is shorter. Side road alternatives do not exist, travel to Port Antonio relies solely upon the Rio Grande Valley Road. Landslide hazard impacts on the Rio Grande Valley Road affect Comfort Castle and many other communities within the valley.

Limited options are available to mitigate the impacts of landslides on the Rio Grande Valley Road to decrease the geophysical vulnerability of Comfort Castle. The physical location is a notable contributing factor to the road's vulnerability that cannot be changed. Improving road quality through better building material and installing retaining walls and a proper drainage system could decrease the severity of landslide impacts to some degree. Although a significant factor to the community's vulnerability of place, addressing geophysical vulnerability is limited by its geographic location and the restricted options to mitigate landslide hazards in the Rio Grande Valley.

Both geophysical and social factors contribute to overall vulnerability (Cutter et al., 2000). Ideally, addressing both would be most beneficial for reducing vulnerability of place. However, in Comfort Castle's case, handling social vulnerabilities is the most feasible, as tackling the geophysical vulnerabilities is difficult. While better road quality would have a limited effect on decreasing geophysical vulnerability and landslide hazard susceptibility, it can reduce the social vulnerability of Comfort Castle considerably. Addressing the root causes, dynamic pressures, and unsafe conditions to reduce social vulnerability will also reduce vulnerability of place. As a result, local capacity is further built and increases the resiliency while decreasing the vulnerability of Comfort Castle to disasters.

\section{Recommendations and Future Work}

Most semi-formal interview participants are with Comfort Castle community members. Additional interviews with residents from Ginger House and Mill Bank to understand their perceptions of local hazards and relationship with the road would 
provide a better understanding of how hazards impact the whole Comfort Castle district. Data collected from Ginger House and Mill Bank may provide site specification hazard perceptions and relationships with the road that differ slightly from Comfort Castle.

Residents from all three communities work and socialize together on a regular basis. The existence and sustainability of these communities rely upon each other. Strengthening Ginger House, Comfort Castle, and Mill Bank by reducing their vulnerabilities to disasters will be beneficial for the entire district.

Only one interview participant was a government official. Interviews were not conducted with more local government officials. In part, due to the limited access of Comfort Castle. However, interviews with additional government officials would provide ethnographic data to enrich the qualitative analysis further. Perspectives on the condition of the Rio Grande Valley Road and along with its impact on community development from government officials would provide a more holistic understanding. Interviews could be facilitated with members of parliament and parish councilors who represent communities in Portland.

Building rapport with participants is critical for building trust and receiving candid responses. The researcher did spend time integrating into the community before conducting semi-formal interviews and made a conscious effort to ensure participants felt comfortable. However, there may have been incidences when participants provided a response, they thought the researcher wanted to hear. Even though a rapport with participants existed, sometimes demeanors change when interviews begin. At times, some participants might have responded to questions they did not fully understand. For these reasons, slight limitations to the qualitative data collected are imminent. It would be difficult to avoid these limitations in future work as they are a part of human nature.

Human error could contribute to minor inaccuracies of the Rio Grande Valley shapefile. Google Earth was used to create the GIS shapefile for the Rio Grande Valley Road is available. Satellite imagery with a high resolution increased the accuracy of the shapefile. However, segments of the road disappear underneath dense foliage coverage. When this occurred, cross-referencing Google Maps assisted in verifying the road's location. Despite the efforts made to ensure accuracy of the road's location, human error could still have a slight impact.

The results from the quantitative data analysis are slightly limited. The analysis only considers where the Rio Grande Valley Road intersects with the landslide susceptibility layer. Impacts from areas of higher susceptibility uphill from areas of lower susceptibility are not accounted for. Landslides in areas of high susceptibility could impact areas of lower susceptibility, therefore increasing the likelihood of a landslide affecting the road and increasing its overall susceptibility. Areas like this are shown for three locations along the Rio Grande Valley Road in figure 5.1. 

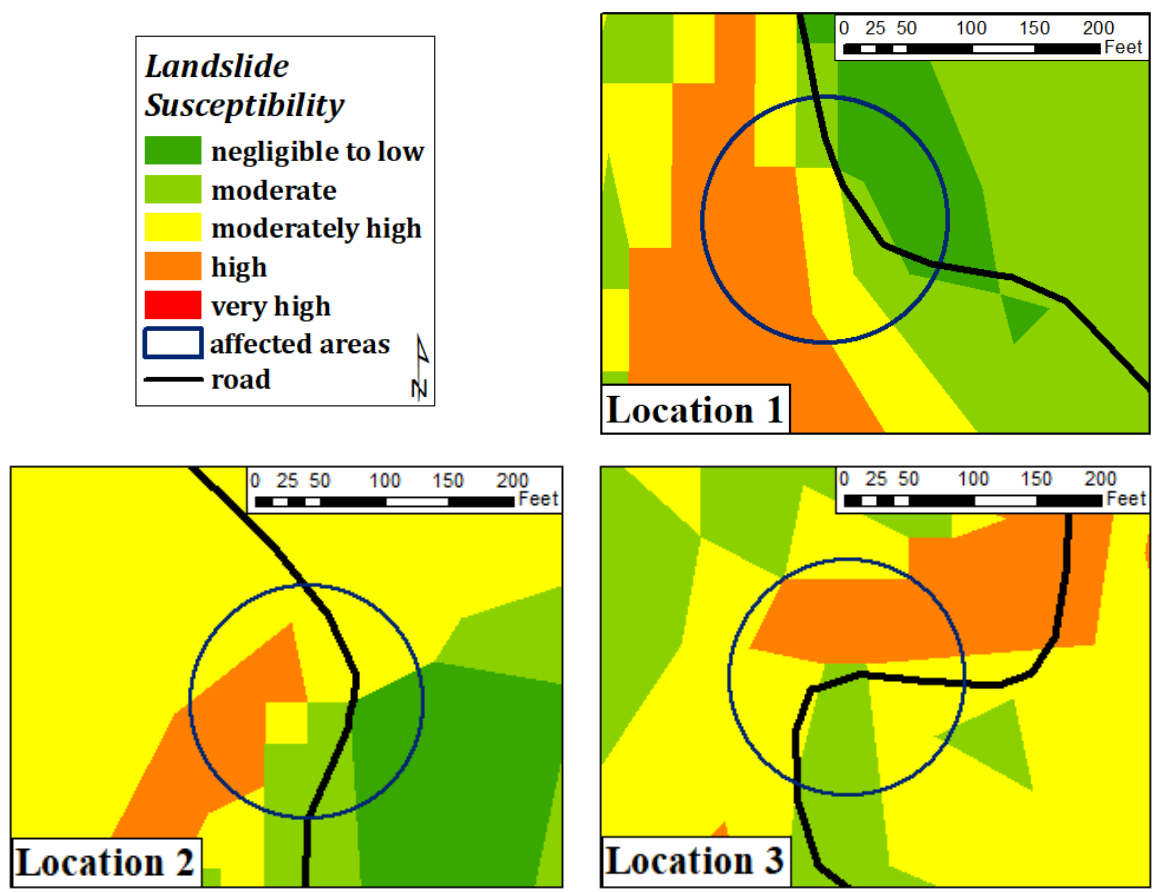

Figure 5.1. Three locations where areas of higher susceptibility could impact lower susceptibility areas that intersect the road. Potentially increasing the levels of landslide susceptibility of these locations.

Consideration was given to this issue before completing the analysis. One possible solution would be to add a buffer around the road to incorporate such encounters. However, the buffer produces a polygon shapefile, and linear distance could not be calculated. The calculation of linear distance is needed to determine how much of the road intersects with the varying levels of landslide susceptibility show in the results section. Future work should look at a way to incorporate the impact of areas of higher susceptibility into the analysis. It would provide a more realistic analysis of the possible impact of landslide hazards on the Rio Grande Valley Road.

Future work should also consider the influence of climate change on the impacts of intensifying or alternating the types of hazards that Comfort Castle experiences. Climate change and a decrease in annual rainfall will likely result in a warmer and drier climate, affecting the frequency, magnitude, and type of natural hazards that the Caribbean region experiences. (Hall et al., 2012; Taylor et al., 2011). Droughts may start to impact areas that once experience a high annual amount of rainfall. The community members could encounter more extreme or new hazard types than it has in its past. It is hard to know the exact effect climate change will have on life in Comfort Castle, solidifying the importance of reducing social vulnerability to build resiliency in anticipation of new and unfamiliar hazards.

Based on the intrinsic relationship between accessibility and vulnerability of place in Comfort Castle, similar research focusing on other site-specific case studies may yield 
similar or new aspects about this relationship. As mentioned previously, improved accessibility does not always lead to increased development for remote or secluded communities. It would be interesting to look at other small rural farming communities with similar accessibility limitations and how its effect on vulnerability in those locations compares to Comfort Castle. Such comparisons would provide a better understanding of the connection between accessibility and vulnerability and the influence of geographic location on their relationship. 


\section{Conclusion}

This thesis demonstrates the impact of accessibility on the vulnerability of place in Comfort Castle to natural hazards. Vulnerability of the community stems from geophysical and socioeconomic characteristics that are exacerbated by poor accessibility. The community's accessibility is reduced by poor road quality, a single access point, increased travel time to Port Antonio, limited livelihood resources, no alternative routes, and mediocre public transportations services. Quality of the Rio Grande Valley Road is the most influential factor of Comfort Castle's accessibility as it plays a significant role in their geophysical and social vulnerability. Installing a proper road is a critical first step to reduce vulnerability of place and mitigate the impacts of natural hazards in the community effectively.

The ethnographic analysis highlights the community's dependency on livelihood resources and illustrates how accessibility is a common denominator among the root causes that affect Comfort Castle and lead to increased vulnerability. All eight of the codes analyzed are exacerbated by the community's limited accessibility, decreasing their resiliency and capacity to respond to disasters as a result. Results of the GIS analyses show the necessity of reducing social vulnerability in anticipation of inevitable future roadblocks from landslide debris due to the Rio Grande Valley Road's susceptibility to landslides. The quantitative and qualitative results show the linking connection between accessibility and vulnerability of place in Comfort Castle.

Mitigating natural hazard impacts requires attenuation of geophysical and social vulnerabilities. In Comfort Castle's case, the most effective way to accomplish this goal is by increasing accessibility. Although challenging, hazard mitigation must start at the deepest level to implement sustainable and successful measures that truly alleviate vulnerability. Improving accessibility provides a platform to address social factors such as political power and representation, financial stability, and education; As well as geophysical factors including distance to markets. Reducing vulnerability related to these factors is difficult without proper access to resources, services, and opportunities for vulnerable populations.

Accessibility directly connects to limited access to political power, structures, and resources and political and economic systems, root causes of the PAR model (Wisner et al., 2004). Mitigating natural hazards through accessibility improvements influences the common denominator among root causes that lead to dynamic pressures and unsafe conditions that generate vulnerability. The quantitative and qualitative analyses reveal how access and place are integral accepts that cannot be separated from geophysical and social vulnerability. Therefore, the causative factors that can limit physical accessibility deserve a more significant emphasis in current vulnerability frameworks such as the PAR and Access models (Wisner et al. 2004). Accessibility can stimulate community development and economic growth, which ultimately reduces vulnerability by increasing resiliency and the capacity to respond to hazard impacts. 


\section{References}

Ahmad R. (1998). Rapid assessment of a landslide disaster in the fellowship area, Rio Grande Valley, Portland, Jamaica. Unpublished paper University of the West Indies, Mona, Kingston.

Bhalai, S. (2007). Landslide Susceptibility of Portland, Jamaica: Assessment and Zonation. [unpublished manuscript]. Mines and Geology Division, Jamaica.

Bhalai, S. (2010). Landslide Susceptibility of Portland, Jamaica: Assessment and Zonation. Caribbean Journal of Earth Science, 41, 39-54.

Blackburn, S. (2014). The politics of scale and disaster risk governance: Barriers to decentralization in Portland, Jamaica. Geoforum, 52, 101-112.

Carby. B. and Ahmad, R., (1995). Vulnerability of Roads and Water Systems to HydroGeological Hazards in Jamaica. Built Environment (1978-), 145-153.

Carby. B, Burrell, D., and Samuels, C. (2012). Jamaica: county document on disaster risk reduction.

Cervero, R. (1990). Accessibility and Third World Rural Development: A Case Study of Sumatra. Review of Urban and Regional Development Studies (2)2, 125-138.

Cutter, S. (1996). Vulnerability of Environmental Hazards. Progress in Human Geography, 20(4), 529-539.

Cutter, S., Mitchell, J. \& Scott, M. (2000). Revealing the Vulnerability of People and Places: A Case Study of Georgetown County, South Carolina. Annals of the Association of American Geographers, 90(4), 713-737.

Cutter, S, Boruff, B., \& Shirley, W. (2003). Social Vulnerability to Environmental Hazards. Social Science Quarterly, 84(2), 242-261.

Davis-Morrison, V., \& Barker, D. (1997). Resource management, environmental knowledge, and decision-making in small farming systems in the Rio Grande Valley, Jamaica. Caribbean Geography, 8(2), 96-106.

Fass, A. J., \& Barrios, R. E. (2015). Applied Anthropology of Risk, Hazards, and Disasters. Human Organization, 74(4), 287-295.

Hall, T. C., Sealy, A. M., Stephenson, T. S., Kusunoki, S., Taylor, M. A., Chen, A. A., \& Kitoh, A. (2012). Future climate of the Caribbean from a super-high-resolution 
atmospheric general circulation model. Theoretical and Applied Climatology, 113(1-2), 271-287. doi:10.1007/s00704-012-0779-7

Ishemo, A., Semple H., Thomas-Hope, E. (2006). Population mobility and the survival of small farming in the Rio Grande Valley. The Geographical Journal, 172(4), 318330 .

Kopytoff, B. K. (1978). The Early Political Development of Jamaican Maroon Societies. The William and Mary Quarterly, 35(2), 287-307.

Lavell, A., \& Maskrey, A. (2014). The future of disaster risk management. Environmental Hazards, 13(4), 267-280. doi: 10.1080/17477891.2014.935282.

Leinbach, T.R. (1994). Transport and Third World Development: Review, Issues, Prescription. Transportation Research Part A, 29(5), 337-344.

McLaughlin, P., \& Dietz, T. (2008). Structure, agency, and environment: Toward an integrated perspective on vulnerability. Global Environmental Change, 18(1), 99111. doi: 10.1016/j.gloenvcha.2007.05.003

Newsome, G.G., and Bruce, H.R. (2003). GPS Coordinate Transformation Parameters for Jamaica. Survey Review, 37(289), 218-234.

Nkemdirim, L. (1979). Spatial and Seasonal Distribution of Rainfall and Runoff in Jamaica. Geographical Review, 69(3), 288-301.

Nyberg, R., \& Johnansson, M. (2013). Indicator of road network vulnerability to stormfelled trees. Natural Hazards, 69(1), 185-199. doi: 10.1007/s11069-013-0693-z.

Oliver-Smith, A. (1999). "What is a disaster? Anthropological Perspectives on a persistent question. The angry earth: Disaster in anthropological perspective (pp. 18-34). Routledge.

Oliver-Smith, A. (2013). Disaster Risk Reduction and Climate Change Adaptation: The View from Applied Anthropology. Human Organization 72(4), 275-282. doi: 10.1111/napa.12089.

Olsson, J. (2009). Improved road accessibility and indirect development effects: evidence from rural Philippines. Journal of Transport Geography, 17(6), 476-483. doi:10.1016/j.jtrangeo.2008.09.001.

Osei, P. D. (2007). Policy responses, institutional networks management and postHurricane Ivan reconstruction in Jamaica. Disaster Prevention and Management: An International Journal, 16(2), 217-234. 
Planning Institute of Jamaica (2010). Vision 2030 Jamaica National Development Plan. Retrieved from http://www.vision2030.gov.jm/.

Planning Institute of Jamaica \& Statistical Institute of Jamaica. (2019). Mapping Poverty Indicators: Consumption-Based Poverty in Jamaica. Retrieved from https://statinja.gov.jm/PublicationReleases.aspx.

Statistical Institute of Jamaica. (2012). Population and Housing Census 2011 Jamaica, General Report (Volume 1). Retrieved from https://statinja.gov.jm/PublicationReleases.aspx.

Taylor, M. A., Sekhar, S. V., \& D’Este, G. M. (2006). Application of Accessibility Based Methods for Vulnerability Analysis of Strategic Road Networks. Networks and Spatial Economics, 8(3-4), doi:267-291. 10.1007/s11067-006-9284-9

Taylor, M.A., Stephenson, T.S., Owino, A., Chen, A.A., \& Campbell, J.D. (2011). Tropical gradient influences on Caribbean rainfall. Journal of Geophysical Research: Atmospheres, 116(D21). doi:10.1029/2010jd015580

UNDP, 2009. Human Development Report 2009 - Jamaica. in World Bank. (2010). Disaster Risk Management in Latin America and the Caribbean Region: GFDRR Country of Jamaica. Washington: USA.

Wilson, F. Towards a Political Economy of Roads: Experiences from Peru. Development and Change, 35(3), 525-546.

Windle, J., \& Cramb, R. (1997). Remoteness and rural development: economic impacts of rural roads on upland farmers in Sarawak, Malaysia. Asia Pacific Viewpoint, $38(1), 37-53$.

Wisner, B., Blaikie, P., Cannon, \& T., Davis, I. (2004). At Risk: Natural Hazards, People's Vulnerability, and Disasters, $2^{\text {nd }}$ Edition. London: Routledge.

Zaman, M. Q. (1999). Vulnerability, disaster, and survival in Bangladesh: three case studies. The angry earth: Disaster in anthropological perspective (pp. 192-212). Routledge. 


\section{A Semi-Formal Interview Questions}

\section{Participant Knowledge of Natural Disasters}

1. How long have you lived in Comfort Castle?

2. Is your family from the area?

a. If not, where are they from?

3. What is a natural disaster?

4. What kind of natural disasters affect Comfort Castle?

5. How have you learned about natural disasters (experience, school, word of mouth?)

6. What has been your experience with natural disasters?

7. Are you aware of natural disaster preparedness and response organization in Comfort Castle?

8. Which types of natural disasters cause the most damage?

9. What type of disaster occurs most frequently (or often)?

\section{Preparedness}

1. Do you prepare for natural disasters?

a. If so, what measures do you take?

2. How do you find out about natural disasters warnings?

3. Does the community prepare for natural disasters?

4. Do you have any skills that help in preparing for or responding to disasters?
a. If yes, what are they?
b. If yes, how did you learn your skill(s)?
c. If yes, are you willing to teach your skill(s) to others?
d. If yes, would you be willing to help others by using your skill(s)?

\section{Past Events}

1. What are some past natural disasters that have affected the community?

2. Did you experience them personally? 
a. If not, how did you learn about them?

3. What impact did they have on the community?

\section{Climate Change}

1. What do you know about climate change?

2. How does it affect Comfort Castle?

3. Have you noticed any change in Comfort Castle's Climate?

\section{Response to Natural Disasters}

1. What do you know about how the government responds to disasters?

2. How effective is their response?

3. Do other organizations outside of the government help with response?

a. If yes, what are they? 


\section{B Rio Grande Valley Road Interview Questions}

1. What has been your experience with the road in Comfort Castle?

2. How does the road impact you personally?

3. How does the road impact the community?

4. Does the road have an impact on natural disasters?

a. If yes, what are those impacts?

5. Is the road important to the community?

a. If yes, why?

6. Who is in charge of repairing the road?

7. How often is the road repaired?

8. Does the road need to be repaired now?

a. If yes, what repairs are needed?

9. Do you remember a time when the road was in good condition? 


\section{Publisher Permission to Reproduce PAR Model}

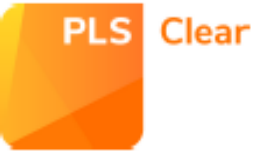

PARTIES:

1. INFORMA UK LIMITED (Company number - 01072954) (Licensor); and

2. Heather Thole (Licensee).

Thank you for your recent permission request. Some permission requests for use of material published by the Licensor, such as this one, are now being facilitated by PLSclear.

Set out in this licence cover sheet (the Licence Cover Sheet) are the principal terms under which Licensor has agreed to license certain Licensed Material (as defined below) to Licensee. The terms in this Licence Cover Sheet are subject to the attached General Terms and Conditions, which together with this Licence Cover Sheet constitute the licence agreement (the Licence) between Licensor and Licensee as regards the Licensed Material. The terms set out in this Licence Cover Sheet take precedence over any conflicting provision in the General Terms and Conditions.

Free Of Charge Licence Terms

Licence Date:

PLSclear Ref No:

The Licensor

Company name:

Address:

The Licensee

Licensee Contact Name:

Licensee Address:

Licensed Material

title:

ISBN:
$14 / 04 / 2020$

36232

INFORMA UK UMITED

4 Park Square

Milton Park

Abingdon

Oxon

OX14 4RN

GB

Heather Thole

6210 NW 2nd Cir Apt 338

Lincoln

68521

United States
At Risk Natural Hazards, People's Vulnerability and Disasters

9780415084765 
publisher:

Are you requesting permission to reuse the cover of the publication? Additional Information
INFORMA UK UMTEDD

Yes

Requesting permission to use figure 2.1 the Pressure and Realise Model found on pg. 51. Will use figure in written master's thesis.

For Use In Licensee's Publication(s)

usage type

Will your dissertation be placed in an online repository?

Author

Estimated publication date

Language

Title of dissertation/thesis

University or institution

Unlimited circulation?

Rights Granted

Exclusivity:

Format:

Language:

Territory:

Duration:

Maximum Circulation:
Book, Journal, Magazine or Academic Paper-Thesis / Dissertation

Yes

Heather Thole

May 27th, 2020

English

The Impacts of Accessibility on Vulnerability to Natural Hazards in Comfort Castle, Jamaica

Michigan Technological University

No

\section{Non-Exclusive}

Thesis / Dissertation

English

USA

Lifetime of Licensee's Edition

\section{GENERAL TERMS AND CONDITIONS}

\section{Definitions and Interpretation}

1.1 Capitalised words and expressions in these General Terms and Conditions have the meanings given to them in the Licence Cover Sheet.

1.2 In this Licence any references (express or implied) to statutes or provisions are references to those statutes or provisions as amended or re-enacted from time to time. The term including will be construed as illustrative, without limiting the sense or scope of the words preceding it. A reference to in writing or written includes faxes and email. The singular includes the plural and vice versa. 


\section{Grant of Rights}

2.1 The Licensor grants to Licensee the non-exclusive right to use the Licensed Material as specified in the Licence Cover Sheet.

2.2 The rights licensed to Licensee under this Licence do not include the right to use any third party copyright material incorporated in the Licensed Material. Licensee should check the Licensed Material carefully and seek permission for the use of any such third party copyright material from the relevant copyright owner(s).

2.3 Unless otherwise stated in the Licence Cover Sheet, the Licensed Material may be:

2.3.1 subjected to minor editing, including for the purposes of creating alternative formats to provide access for a beneficiary person (provided that any such editing does not amount to derogatory treatment); and/or

2.3.2 used for incidental promotional use (such as online retail providers' search facilities).

2.4 Save as expressly permitted in this Licence or as otherwise permitted by law, no use or modification of the Licensed Material may be made by Licensee without Licensor's prior written permission.

\section{Copyright Notice and Acknowledgement}

3.1 Licensee must ensure that the following notices and acknowledgements are reproduced prominently alongside each reproduction by Licensee of the Licensed Material:

3.1.1 the title and author of the Licensed Material;

3.1.2 the copyright notice included in the Licensed Material; and

3.1.3 the statement "Reproduced with permission of The Licensor through PLSclear."

\section{Reversion of Riqhts}

4.1 The rights licensed to Licensee under this Licence will terminate immediately and automatically upon the earliest of the following events to occur:

4.1.1 the Licensed Material not being used by Licensee within 18 months of the Licence Date;

4.1.2 expiry of the Licence Duration; or

4.1.3 the Maximum Circulation being reached.

\section{Miscellaneous}

5.1 By using the Licensed Material, Licensee will be deemed to have accepted all the terms and conditions contained in this Licence.

5.2 This Licence contains the entire understanding and agreement of the parties relating to its subject matter and supersedes in all respects any previous or other existing arrangements, agreements or understandings between the parties whether oral or written in relation to its subject matter.

5.3 Licensee may not assign this Licence or any of its rights or obligations hereunder to any third party without Licensor's prior written consent.

5.4 This Licence is governed by and shall be construed in accordance with the laws of England and Wales and the parties hereby irrevocably submit to the non-exclusive jurisdiction of the Courts of England and Wales as regards any daim, dispute or matter arising under or in relation to this Licence. 